\title{
Porous Shape Memory Polymers
}

\author{
Keith Hearon ${ }^{1,{ }^{* *}}$, Pooja Singhal ${ }^{1,2,{ }^{* *}}$, John Horn ${ }^{1}$, Ward Small IV ${ }^{2}$, Cory Olsovsky ${ }^{1}$, Kristen \\ C. Maitland ${ }^{1}$, Thomas S. Wilson ${ }^{2}$, and Duncan J. Maitland ${ }^{1, *}$ \\ ${ }^{1}$ Department of Biomedical Engineering, Texas A\&M University, College Station, TX, United \\ States of America
}

${ }^{2}$ Lawrence Livermore National Laboratory, Livermore, CA, United States of America

\begin{abstract}
Porous shape memory polymers (SMPs) include foams, scaffolds, meshes, and other polymeric substrates that possess porous three-dimensional macrostructures. Porous SMPs exhibit active structural and volumetric transformations and have driven investigations in fields ranging from biomedical engineering to aerospace engineering to the clothing industry. The present review article examines recent developments in porous SMPs, with focus given to structural and chemical classification, methods of characterization, and applications. We conclude that the current body of literature presents porous SMPs as highly interesting smart materials with potential for industrial use.
\end{abstract}

\section{Introduction}

Complex engineering challenges often require advanced solutions, and the emergence of smart materials has inspired innovation in a diverse array of scientific fields. Shape memory polymers (SMPs) offer novel materials-based avenues to solving scientific challenges because of their demonstrated ability to actively undergo geometric transformations upon exposure to environmental stimuli such as heat, light, and solvents or moisture. ${ }^{[1,2]}$ The shape memory effect, first reported for polymers in crosslinked polyethylene for heat-shrink applications in the 1950s, has been reported for numerous polymer systems and is wellcharacterized in the literature ${ }^{[3,4]}$ The ability of materials to store a temporary geometry and then actuate to a primary geometry has driven SMP-based research in fields ranging from biomedical engineering and aerospace engineering to the fashion and culinary industries. Medical devices that change shape after insertion into the body, satellite components that self-actuate after heat exposure, and fabric materials that shrink away from moisture sources are just a few examples of proposed SMP-based applications. ${ }^{[5,6]}$ In Figure 1, the shape memory cycle for a one-way, thermally actuated SMP is illustrated in terms of stress/temperature, stress/strain, and strain/temperature planes. Step 1 is isothermal loading, Step 2 is cooling at constant load, Step 3 is isothermal unloading, and Step 4 is shape recovery upon heating under load-free conditions. Because multiple reviews of shape memory polymers exist in the literature, the well-known entropy-driven mechanism of the shape memory effect is not discussed in further detail in this review.

Porous shape memory polymeric materials possess certain material capabilities that neat SMPs do not possess, including greater volumetric expansion capability and stimuliresponsive dynamic permeability capability upon actuation. After actuation, porous SMPs

*Corresponding Author Duncan J. Maitland, PhD Associate Professor, Texas A\&M University, Biomedical Engineering, Mailstop 3120, 5045 Emerging Technologies Building, College Station, TX 77843 (o) 5057 ETB (w) 979.458.3471 djmaitland@ tamu.edu. These authors contributed equally to this manuscript. 
can elicit porosity-dependent environmental responses, which make them excellent candidate materials for applications such as tissue scaffolds, in which porosity and pore size often influence physiological responses. ${ }^{[7]}$ Porous SMPs are defined in this review as any SMP possessing a porous three-dimensional macrostructure. Traditionally, porous polymers have been defined as polymeric substrates that, after introduction to porogens (salt particulates, gaseous blowing agents, solvents, etc.) during curing or thermoplastic processing, can be made to have porous macrostructures by poragen removal. ${ }^{[8]}$ Recent review articles have also defined electrospun polymer meshes, three dimensional micropatterned scaffolds, and other templated cellular materials as "porous."[9]

While both "shape memory polymers" and "porous polymers" have been the focus of multiple reviews in the literature, the topic of "porous shape memory polymers" has yet to receive the sole focus of a literature review article as is the purpose of this article. We have limited our survey of porous SMPs to those containing pore structures on the order of micrometers or larger. We leave the topic of nanostructured porous media (e.g. shape memory hydrogels ${ }^{[10]}$ ) to other reviews.

In this manuscript we first survey methods used to fabricate porous SMP materials and identify classes of SMPs based on their chemical composition. Next, we review various techniques used to characterize physical properties and mechanical behavior of porous SMPs and report results for specific materials. Finally, we discuss several applications for these materials. For example, many of the first proposed applications for porous SMPs were SMP foam-based actuators in the aerospace industry. ${ }^{[11,12]}$

\section{Methods of Fabrication of Porous SMP Materials}

Numerous techniques have long been utilized in the fabrication of porous polymeric substrates. Various pore sizes, geometries, and degrees of uniformity can be achieved in a highly diverse array of polymeric systems, and together both architectural framework and chemical makeup largely dictate material behavior. Because in-depth reviews of porous polymer fabrication techniques exist in the literature, this review focuses on such fabrication techniques only as they pertain to porous shape memory polymers and their material capabilities, which are summarized in Table 1. For in-depth discussions of porous polymer fabrication methods, the authors recommend review articles by Hentze and Antonietti, ${ }^{[13]}$ Ravichandran, et al.,, ${ }^{[14]}$ and Bettinger. ${ }^{[15]}$

\subsection{Foaming}

Perhaps the first and most frequently reported method of porous SMP fabrication is foaming, which can be used to produce both thermoplastic and thermoset SMP foams with average porosities of 0.8 to 0.95 or higher. ${ }^{[16]}$ These foams are generally isotropic and can be either open- or closed-celled, with pore sizes varying from the sub-micron range to the $\mathrm{mm}$ range. ${ }^{[17]}$ During foaming, pores are created by gas generation, which may occur by chemical reactions or by the evaporation of blowing agents after heating and/or pressure changes. Multiple studies report foaming in polyurethane SMPs by chemical blowing processes, such as those in which $\mathrm{CO}_{2}$ is generated by adding water to isocyanate-containing premixes during curing. ${ }^{[18,19]}$

An interesting case involves the use of supercritical $\mathrm{CO}_{2}\left(\mathrm{scCO}_{2}\right)$ for foaming. Carbon dioxide initially acts as a solvent for monomers or thermoplastic polymers under highpressure conditions and then subsequently acts as a blowing agent after pressure release. Since various catalysts and surfactants, which may contain toxic heavy metal cations, are often required for foaming, $\mathrm{scCO}_{2}$ foaming is generally considered a greener process than other foaming techniques. Lendlein and co-workers have reported the use of $\mathrm{scCO}_{2}$ foaming 
in the fabrication of biodegradable poly(ع-capralactone) SMP foams. ${ }^{[20]}$ Simkevitz and Naguib utilized $\mathrm{scCO}_{2}$ foaming to create $\mathrm{SMP}$ foam/organoclay nanocomposites from the CRG Inc. styrene-based Veriflex SMP. ${ }^{[21]}$

\subsection{Syntactic Foams}

Syntactic polymer foams are special closed-celled composite foams that contain hollow microparticles dispersed in a polymer matrix. Syntactic foams are generally prepared by physically blending hollow particles such as hollow glass microbeads in a liquid prepolymer resin and then curing the resin around the hollow microbeads. Syntactic foams often exhibit highly tailorable material properties, which depend largely on microparticle size and composition. Li and co-workers have reported an SMP syntactic foam comprised of the CRG Inc. styrene-based Veriflex ${ }^{\circledR}$ SMP and $40 \%$ by volume glass microspheres. By applying biaxial stresses to these syntactic foams, they could be made to exhibit auxetic behavior (i.e., a negative Poisson's ratio). Auxetic materials, which expand horizontally when stretched axially and contract horizontally when compressed axially, may have unique industrial applications, such as novel sealants and cushions. ${ }^{[22]}$

\subsection{Particulate Leaching}

Another technique commonly used in porous SMP fabrication is salt leaching, which is used to prepare SMP scaffolds for soft tissue, drug delivery, and other biomedical engineering applications. ${ }^{[23]}$ For scaffolds made by salt leaching, porosities have been reported in the $0.20-0.90$ range and average pore sizes in the $30-120 \mu \mathrm{m}$ range. One of the main advantages of salt leaching is that it is a relatively easy laboratory technique to perform, while one of its main disadvantages is that it only provides limited control of three-dimensional substrate structures. ${ }^{[24]}$ In salt leaching, a salt such as sodium chloride is added to a monomer/ crosslinker or thermoplastic polymer solution in an organic solvent such as THF. After curing (if necessary) and film casting by solvent evaporation, solid polymeric films containing salt particulates remain, and leaching the particles in water results in the formation of porous polymer substrates. Salt fusion, first reported by Murphy, et al. in 2002, involves partially fusing the salt poragen prior to polymer curing and allows for improved pore interconnectivity. ${ }^{[25]}$ Grunlan and co-workers utilized salt fusion to fabricate a unique organic-inorganic porous thermoset SMP made from acrylated polydimethylsiloxane and poly( $\varepsilon$-caprolactone) macromers, as illustrated in Figure 2. ${ }^{[26]}$ Numerous other SMP scaffolds exhibiting shape memory capabilities have also been prepared using salt leaching or salt fusion. ${ }^{[27-30]}$

\subsection{Electrospinning}

Electrospinning, which is illustrated in Figure 3, is a process by which nano- or micro-scale polymeric fibers are deposited via applied electric potential onto a grounded target to create non-woven meshes. Electrospinning has become an increasingly prevalent fabrication technique in tissue engineering studies. Electrospun meshes, which structurally resemble the extracellular matrices (ECMs) of certain tissue types, have been proposed for applications ranging from vascular grafts to filtration membranes. Advantages of electrospinning include high achievable porosities and high surface-to-volume ratios, while disadvantages include poor mechanical integrity and limited control over micro-architecture. ${ }^{[31]}$ Tseng, et al. recently reported an electrospun SMP scaffold mesh capable of undergoing fiber structure realignment upon heating from 30 to $37^{\circ} \mathrm{C}$, which resulted in a shift in cell orientation towards the scaffold during cell culture studies. ${ }^{[32]}$ Youk and co-workers reported an electrospun membrane exhibiting two-way shape memory behavior, which could reversibly undergo shifts in pore size between 150 and $440 \mathrm{~nm}$ upon heating under constant loading conditions. ${ }^{[33]}$ Zhou and co-workers recently reported a magnetically active electrospun 
SMP nanocomposite capable of remote actuation as a platform for creating multi-functional tissue engineering scaffolds. ${ }^{[34]}$

\subsection{Cell Membrane Reticulation}

The fabrication techniques and process parameters used to create porous materials largely dictate whether they will exhibit open-celled, closed-celled, or mixed cellular morphology. Certain applications require that cells be partially or fully interconnected (i.e., open celled). For example, tissue scaffolds, which are designed to allow cell growth to proceed through the scaffold matrix, generally require open celled structures. If the cellular membranes in a closed celled substrate are thin enough, post-processing techniques such as acid etching may be employed to remove cell membranes and improve cell interconnectivity. ${ }^{[35]}$ In one example, reported by De Nardo, et al., plasma sterilization treatments increased open cell content by up to $29 \%$ for select Mitsubishi SMP foams ${ }^{[36]}$. Continued studies by De Nardo found that ozone sterilization performed on Mitsubishi SMP foams also appeared to improve cell interconnectivity ${ }^{[37]}$.

\subsection{Other Fabrication Methods}

Other fabrication techniques used to create porous SMP substrates include thermally induced phase separation, ${ }^{[38]}$ high internal phase emulsion, ${ }^{[39]}$ stereolithography, ${ }^{[40]}$ and solid-state foaming. ${ }^{[41]}$ Although these fabrication methods are not in themselves described in this review, porous SMPs made by these techniques are discussed in later sections.

\section{Chemical Classes of Porous SMPs}

Table 2 summarizes chemical classes of porous SMPs including material and physical properties.

\subsection{Commercially Available SMPs}

3.1.1 Mitsubishi Heavy Industries Polyurethane Thermoplastic SMP-One of the most widely known commercially available shape memory polymers in the literature is that of Mitsubishi Heavy Industries. The Mitsubishi SMPs are thermoplastic polyurethanes, and the proprietary polyether polyol prepared by chemical foaming. ${ }^{[16]}$ The Mitsubishi SMPs are thermo-mechanically characterized in numerous studies, especially those of Sokolowski, Hayashi, and co-workers. ${ }^{[42]}$ Additionally, Metcalfe, et al. performed cytotoxicity testing, ${ }^{[43]}$ and De Nardo, et al. evaluated the effects of plasma and ozone sterilizations. ${ }^{[37]}$

De Nardo also reported foaming of the Mitsubishi MM4520 SMP by three methods: (i) coextrusion with chemical blowing agents, (ii) co-extrusion with sodium chloride $(\mathrm{NaCl})$, followed by particulate leaching, and (iii) solvent casting/particulate leaching. ${ }^{[4]}$ Using the various material properties of the MM5520 SMP, Restrepo and co-workers recently proposed periodic cellular materials using a non-linear finite element analysis (FEA). ${ }^{[45]}$

\subsubsection{Cornerstone Research Group (CRG) Styrene Thermoset SMP Resin}

(Veriflex)-The commercially available two-part thermoset SMP resin produced by Cornerstone Research Group (CRG) has also gone by the trade name "Veriflex."[21] Numerous studies have reported the fabrication and characterization of porous SMPs based on this family of resins. $\mathrm{Li}$ and $\mathrm{Xu}$ reported a syntactic foam containing $40 \%$ hollow glass microparticles. ${ }^{[46]}$ Perkins, et al. proposed adaptive wing structures using this same SMP. [47] Recently, Lu and Gou reported a CRG Veriflex nanocomposite resin incorporated into a self-assembled multi-walled carbon nanotube nanopaper that exhibits electroactive behavior. ${ }^{[48]}$ 


\subsubsection{Composite Technology Development (CTD) SMP Foams-The}

commercially available TEMBO $3 \mathrm{XE}$ foam is a two-part thermoset epoxy foam. DiPrima and co-workers performed a comprehensive thermo-mechanical characterization of it as they investigated it for potential use in aerospace applications. ${ }^{[49]}$ The TEMBO DP5.1 foam was also characterized by multiple groups, including Radford and Antonio, ${ }^{[50,51]}$ Vialle, ${ }^{[52]}$ and DiPrima. ${ }^{[53]}$

3.1.4 Other Commercial Materials-Other commercial SMP systems have been used to make porous SMPs. A one part heat curable epoxy resin, Scotchkote $206 \mathrm{~N}$ from $3 \mathrm{M}$, has been used to fabricate foams using insertion in a muffle-furnace at $320{ }^{\circ} \mathrm{C}$ for $8 \mathrm{~min}$, followed by cooling in air. ${ }^{[41,54,55]}$ Porous Calomer 48 SMP (Polymer Technology Group, Berkeley) has been fabricated via foaming and particulate leaching process by DeNardo et al. ${ }^{[30,44]}$ An SMP foam under the trade name of FLEGMAT from Ranwal Ltd has also been reported in literature. ${ }^{[56]}$

\subsection{Non-Commercially Available SMP Porous Materials}

3.2.1 Polyurethane SMP Porous Substrates-Wilson and co-workers have reported on the synthesis and characterization of low density thermoset polyurethane SMP foams prepared using a batch foaming method ${ }^{[57]}$. The stated application of these foams, which are prepared from aliphatic polyol and diisocyanate monomers for biocompatibility, is an interventional brain aneurysm occlusion device. ${ }^{[35,58-60]}$ Chung and Park fabricated polyurethane SMP foams from a segmented thermoplastic polyurethane using salt leaching, ${ }^{[27]}$ and Chung, Kang, and co-workers also fabricated an electrospun web using the same thermoplastic polyurethane. ${ }^{[61]}$ Domeier ${ }^{[62]}$ and Lee ${ }^{[19]}$ also studied polyurethane based SMP foams (Table 1).

3.2.2 Poly( $\varepsilon$-caprolactone)-Containing SMP Porous Substrates-Multiple porous SMPs that utilize the crystalline melt transition of polycaprolactone (PCL) as a switching segment have been reported by various fabrication techniques. Mather and co-workers recently reported a porous, crosslinked PCL-based bone scaffold prepared using salt leaching that exhibited shape memory capabilities. ${ }^{[63]}$ Lendlein and co-workers performed an extensive analysis of the nucleation mechanisms that occurred during the attempted $\mathrm{scCO}_{2}$ foaming of both molten and solid PCL thermoplastics, of which foaming only occurred in the molten state. ${ }^{[64]}$ Zhou and co-workers achieved magnetically-induced remote actuation in electrospun thermoset PCL composite matrices that contained multiwalled carbon nanotubes coated with $\mathrm{Fe}_{3} \mathrm{O}_{4}$ nanoparticles. ${ }^{[34]}$

\section{Characterization of Porous SMP Substrates}

\subsection{Density}

The density of polymeric porous materials is arguably the most influential of all physical attributes on mechanical properties. High-density porous materials exhibit significantly different mechanical behavior than to low-density porous materials, and density is also highly influential over environmental response to porous materials after introduction to new environments. ${ }^{[65]}$ The characterization of porous SMP materials includes both bulk material properties as well as three-dimensional structure analysis. Some standards typically used for measurement of density include ISO845, ASTM D1622 and ASTM D2856-94. These standards emphasize the importance of using large enough sample sizes to account for the inherent variance or defects in cell uniformity. Measurements of the sample dimensions become more difficult as the materials reach much lower densities, and care should be taken to not compress them during measurement. Porosity or fractional void volume is directly related to density ( $\varepsilon=1-\rho_{\mathrm{f}} / \rho_{\mathrm{p}}$ where $\mathrm{f}$ and $\mathrm{p}$ stand for foam and polymer respectively) and 
often alternately with density. Porous SMP materials with various densities have been reported in the literature and have been summarized in Table 1.

Density is largely dependent on the fabrication technique used to create a porous material. For foams, certain blowing processes have enabled very low densities to be achieved. For example, the thermoset polyurethane foam reported by Singhal, et al. exhibited low density $\left(\sim 0.015 \mathrm{~g} / \mathrm{cm}^{3}\right) \cdot{ }^{[35]}$ Densities in the range of $0.032 \mathrm{~g} / \mathrm{cm}^{3}{ }^{[43]}$ to $\sim 0.120 \mathrm{~g} / \mathrm{cm}^{3}{ }^{[36]}$ were also reported for foams made from the Mitsubishi SMPs, although their specific method of production is proprietary. Simkevitz reported notably higher densities for $\mathrm{scCO}_{2}$-blown CRG Veriflex styrene thermoset SMP foam nanocomposites, in which relative densities were tailorable between $30 \%$ and $90 \%$ by varying foam saturation pressure and foaming time. ${ }^{[66]}$ The epoxy-based Composite Technology Development (CTD) TEMBO® DP5.1 foams characterized by DiPrima et al. were shown to have $20 \%, 30 \%$ and $40 \%$ relative densities. ${ }^{[52,53,67,68]}$. Domeier studied high density "tough" urethane SMPs with porosities from 25 to $75 \%$ and closed cell structure. ${ }^{[62]}$

In comparison with the low density foam blowing processes, particulate leaching often results in higher densities. For example, for the PCL-polydimethylsiloxane (PDMS) SMP scaffold prepared by Grunlan and co-workers using salt fusion, the reported relative density was in the range of $20-30 \%$ (reported porosity values $\sim 72 \%$ to $\sim 86 \%$ ) $^{[26]}$. Chung and Park achieved a density of $\sim 0.11 \mathrm{~g} / \mathrm{cm}^{3}$ for the PCL-polyurethane that they fabricated using salt leaching. ${ }^{[27]}$ A comparable porosity, $\sim 82 \%$, was reported for the magnetroresponsive electrospun mesh reported by Zhou and co-workers. ${ }^{[34]}$ Higher densities, in the range of 0.30 to $0.65 \mathrm{~g} / \mathrm{cm}^{3}$, resulted from the solid state foaming processes reported by Quadrini, et al. ${ }^{[41]}$

\subsection{Cell Structure}

In porous polymeric substrates, cell size, homogeneity, open/closed structure, and strut/ membrane thickness are all important factors that influence material behavior. Fatigue life, modulus, shape recovery capability, and environmental response, in addition to other properties, are highly dependent on cell structure. X- ray CT scan (including micro-CT), SEM, and optical microscopy are generally used in cell structure analysis. For centimeter to micron level cell sizes, optical microscopy may be used effectively in cell characterization, as shown in Figure 4. Cell sizes from these 2D images may be estimated using the algorithm in ASTM D3576 by counting the number of intersections of pore walls with a reference line. Planar 2D images of porous surfaces are also often reported using SEM, such as the SEM images of the porous SMPs fabricated by electrospinning and salt leaching, reported by Chung, et al. ${ }^{[27,61]}$, as shown in Figure 5. While 2D images are informative, three dimensional structures allow for a more comprehensive structural characterization. 3D renderings of SMP foam structures by X-ray micro CT scanning, such as that reported by DiPrima, shown in Figure 6, provide excellent cell structural information ${ }^{[49]}$. Direct distance transformation methods can be used for characterization of the shape, size and distribution of cells in the $\mathrm{CT}$ generated 3D structural rendering. ${ }^{53]}$

Pore interconnectivity is an important parameter that defines the openness of a porous structure. While it can be estimated qualitatively from 2D SEM images ${ }^{[26]}$, other quantitative methods have also been reported. DiPrima, et al. calculated the pore interconnectivity for the CTD TEMBO DP5.1 epoxy foams based on the volume normalized measure of redundant connections among struts using Euler characteristics, which was found to be 292 to $800 \mathrm{~mm}^{-3}$ for the $20 \%$ to $40 \%$ relative density foams. ${ }^{[53]}$ Pycnometry, as specified by ASTM D6226-10, is an experimental method for measuring pore interconnectivity. 
Confocal microscopy is a technique that has potential as a method of characterizing the high-fidelity 3D structure SMP foams. Currently it is being pursued by the authors as synergistic method with micro-CT scans for imaging porous SMP structures. While micro$\mathrm{CT}$ provides overall strut architecture, the resolution does not permit imaging of the micron and sub-micron thick membranes. While gas sorption measurements can provide surface areas on open-celled foams, it does not work well for closed, or partially closed, cell foams. Also, gas sorption methods do not provide micro-structure architecture that is needed for detailed flow simulations. There is potential to use micro-CT to provide sampled detailed high resolution images of foams pores (or whole foam samples). Figure 7 shows a confocal image of SMP foam using a water immersion objective (unpublished). A thermoset polyurethane foam sample was first immersed in water and evacuated to remove bubbles. An image stack of the foam was collected with an inverted confocal microscope (Lucid Vivascope 2500) in fluorescence mode using $488 \mathrm{~nm}$ illumination (lateral field of view: $750 \times 750$ um$^{2}$, pixel size: 0.75 um, z-step spacing: 4.7 um, image stack depth: 700 um). ImageJ was used to despeckle the noise, adjust the white/black level, and scale the stack so the voxel was cubed. The stack was then rendered into a 3D volume using MedINRIA software.

\subsection{Thermal Characterization}

The shape memory effect is achieved, typically, in one-way, thermally actuated SMPs by heating or cooling polymers about a thermal transition temperature, $T_{\text {trans }}$, to enable some combination of geometric programming, shape fixity, and shape recovery. $\mathrm{T}_{\text {trans }}$ may be a glass transition $\left(\mathrm{T}_{\mathrm{g}}\right)$, crystalline melt transition $\left(\mathrm{T}_{\mathrm{m}}\right)$, or some other transition, such as a supramolecular or ionomeric dissociation. ${ }^{[69]}$ Differential scanning calorimetry (DSC) is one of the most widely reported experimental methods used to characterize polymeric thermal transitions. For amorphous SMP foams, DSC can be used to predict the temperature at which shape recovery will begin - the onset of the glass transition - and can also be used to calculate percent crystallinity and enthalpies of melting or fusion for semicrystalline SMPs.

It is often desirable for the thermal transitions in SMP systems to be tunable so that actuation temperature can be tailored to meet the demands of the specific application. For the Mitsubishi SMP foam series, $\mathrm{T}_{\mathrm{g}}$ range has been reported experimentally to be 30 to $60^{\circ} \mathrm{C} \cdot{ }^{[70-72]} \mathrm{A}$ comparable $\mathrm{T}_{\mathrm{g}}$ range of 45 to $70^{\circ} \mathrm{C}$ was reported for a low-density thermoset polyurethane foam system, and DSC overlays illustrating this $\mathrm{T}_{\mathrm{g}}$ variation are provided in Figure 8(a). Table 1 contains the thermal transition data for other porous SMPs discussed in this review. It is important to note that SMP actuation temperatures can be significantly influenced by shape memory programming history, especially in the case of physically crosslinked polymers. Cui and co-workers have reported a radio-opaque, PEU thermoplastic SMP composite scaffold with actuation temperatures tailorable from 35 to $60^{\circ} \mathrm{C}$ by varying deformation temperature during programming. ${ }^{[73]}$ Figure $8(b)$ illustrates how isothermal recovery rate of this SMP at $37^{\circ} \mathrm{C}$ appeared to proceed more and more slowly as straining temperature was increased from 40 to $60^{\circ} \mathrm{C}$.

Many polymeric materials exhibit plasticization when subjected to ambient moisture, solvents, and other plasticizers. Because porous polymers often have significantly greater surface areas than neat polymers, plasticization generally occurs much more rapidly in porous substrates. During plasticization, increased polymer chain mobility results in $T_{g}$ depression, which can be significant (on the order of $100^{\circ} \mathrm{C}$ or greater) and can significantly alter polymeric material properties. Polyurethanes are especially prone to moisture-induced plasticization because water molecules can occupy intermolecular hydrogen bonding sites between chains, which would otherwise act as physical crosslinks and restrict chain mobility. In $2011 \mathrm{Yu}$, et al. ${ }^{[60]}$ reported an in-depth characterization of the plasticization 
effects of environmental humidity on the low-density thermoset SMP foams characterized by Singhal. ${ }^{[35]} \mathrm{Yu}$ reported a maximum $\mathrm{T}_{\mathrm{g}}$ depression of about $60^{\circ} \mathrm{C}$ for polyurethane foams subjected to $100 \%$ relative humidity (i.e., immersion in a water bath), and this $\mathrm{T}_{\mathrm{g}}$ depression occurred in less than $24 \mathrm{~h} .{ }^{[60]}$ Figure 9 illustrates that the magnitude of $\mathrm{T}_{\mathrm{g}}$ depression increased with increasing relative humidity and increasing humidity exposure time for the SMP foams in Yu's study. Because plasticization can cause such significant changes in porous SMP material properties, moisture at times acts antagonistically toward SMP devices by driving premature actuation and at other times acts functionally by providing an additional avenue for actuation other than heating (i.e., moisture-induced actuation). Recently, the chemistry, based on the hydrophobicity of the isocyanate monomer, of polyurethane SMP foams was used to control the body-temperature actuation rate in water. ${ }^{[74]}$

\subsection{Dynamic Thermo-Mechanical Characterization}

Dynamic mechanical analysis (DMA) can be employed to measure numerous temperature and frequency-dependent properties of polymers, including glassy and rubbery modulus, which are very important properties for SMPs. DMA characterization of porous materials using tensile, cantilever, or torsional instrument modes can be challenging because of sample loading difficulties, although strategies such as embedding the SMP foam ends in epoxy resins and securing the samples at the cured epoxy sites are possible. Compression DMA testing of porous SMPs allows for much easier loading of foam samples, although this improvement often comes with a tradeoff in experimental precision-especially for lowdensity foams. Quadrini, et al. reported that replacing one of the platens in a Netzsch DMA $242 \mathrm{C}$ with a thinner aluminum plate resulted in improved instrument response during sample set-up because of reduced mechanical and thermal inertia. ${ }^{[41]}$ DMA provides a recordable metric of quantifying crosslink density in ideal elastomeric thermosets (rubbery modulus) and is also used to determine the temperatures at which theoretical maximum toughness $\left(\mathrm{T}_{\text {loss modulus peak }}\right)$ and maximum strain $\left(\mathrm{T}_{\text {tan delta peak }}\right)$ occur for polymeric systems. Determining the maximum toughness state of a polymer is especially important when selecting the shape memory programming temperatures for SMPs with poor mechanical integrity, such as some electrospun SMP scaffolds and low-density SMP foams. SMP porous materials often cannot survive deformation into secondary geometries unless they are strained at temperatures in or near their tough regimes, and consequently DMA characterization should generally precede any potentially destructive processes.

Relating Modulus and Relative Density for Porous SMPs-The Gibson- Ashby model on cellular solids attempts to relate the relative density and modulus of cellular solids under various deformation mechanism conditions. ${ }^{[75]}$ The equation for an open celled solid exhibiting linear elastic deformation behavior states that foam elastic stiffness is proportional the square of its relative density,

$$
E^{*} / E_{s} \approx\left(\rho^{*} / \rho_{s}\right)^{2}
$$

where $E^{*}$ is foam modulus, $E_{S}$ is the bulk material, $\rho^{*}$ is foam density, and $\rho_{S}$ is bulk material density. DiPrima and co-workers employed this relationship to predict modulus values for three CTD TEMBO ${ }^{8}$ DP5.1 epoxy foams with relative densities of $20 \%, 30 \%$, and $40 \%$ and then evaluate the accuracy of these predications by running DMA experiments on the epoxy foams and the constituting resin. ${ }^{[53]}$ DiPrima determined that the GibsonAshby model was accurate in predicting the modulus values of the open celled foams under linear elastic deformation. He also determined that this same model was mostly accurate in describing the stress-strain behavior of the foams, although one modification of the model 
was needed to account for the fact that densification strain (i.e., the point at which the stressstrain response of a foam stiffens because of cell wall contact) exhibited temperaturedependent behavior.

\subsection{Tensile Testing}

Tensile testing is performed on porous SMPs to determine modulus, yield stress, strain-tofailure, stress-at-failure, and toughness. These properties largely determine the application range for porous shape memory materials. Proper gripping of porous tensile testing specimens requires that the specimen suffer no cellular damage as a result of the gripping process. Embedding foam ends in an epoxy resin or some other neat polymer has generally allowed for successful tensile testing experiments. ${ }^{[60]}$ The straining temperature(s) in strainto-failure studies should be carefully selected based on targeted application requirements or for specific materials characterization purposes. As Figure 9 illustrates, moisture absorption can cause significant depression of $\mathrm{T}_{\mathrm{g}}$, and such shifting can in turn alter stress-strain behavior. For the foams in that study, Yu et al. reported a variation in the Young's modulus of SMP foams of $35-281 \mathrm{kPa}$, and strain-to-failure of $18-41 \%$ based on their moisture content. ${ }^{[60]}$ A syntactic foam prepared by dispersing glass microspheres in the Veriflex SMP resin ( $40 \%$ by volume) was characterized in both primary and secondary shapes in various aging conditions, including exposure to UV light, rainwater, and saltwater. ${ }^{[76]}$ For the primary geometry, a $4.6 \%$ decrease in stress-at-failure and an $11.4 \%$ decrease in strainto-failure were observed after aging, and these respective values increased to $7.3 \%$ and $15.1 \%$ for the secondary geometry. This behavior was explained in regards to photooxidation (i.e., the generation of oxidative species, $\mathrm{C}-\mathrm{O}, \mathrm{C}=\mathrm{O}, \mathrm{COOH}$, etc.) caused by heating and polymer-photon interactions in the presence of UV light. Modulus increases of $7.6 \%$ for the primary geometry and $9.2 \%$ for the secondary geometry were also reported, which was thought to be the result of potential crosslinking reactions in the material in the presence of these oxidative species.

DiPrima tested the strain-to-failure at different temperatures in the epoxy based TEMBO 3XE (CTD) SMP foams at a specific strain rate of $0.0025 \mathrm{~min}^{-1}$ to determine the temperature at which maximum strain before failure was obtained. The maximum value of strain-to-failure for the TEMBO DP5.1 (CTD) foams, nearly two times that of any other straining temperature, was seen at $\sim 93{ }^{\circ} \mathrm{C}$, which is near the loss modulus peak. ${ }^{[53]}$

\subsection{Characterization of Shape Memory Behavior}

One of the major reasons for interest in SMP foams is their ability to be compacted to a higher density (smaller volume) state that can then be actuated to a lower density (larger volume) state. Consequently, thermo-mechanical shape memory characterization of these materials is mostly done in the compressive mode, although tensile tests have been reported. ${ }^{[44]}$ Shape memory characterization involves 3-4 primary steps, including sample loading at $\mathrm{T}>\mathrm{T}_{\text {trans }}$ and then cooling/fixing by cooling to $\mathrm{T}<\mathrm{T}_{\text {trans }}$ while maintaining the strain from loading. The fixed sample can then either be taken through free strain recovery by heating to $T>T_{\text {trans }}$ under no load, or constrained stress recovery by heating to $T>T_{\text {trans }}$ while maintaining the strain. Load may be removed after constrained stress recovery to estimate the ultimate strain recovery of the sample, as shown in Figure 10.

The stress-strain curve during the loading/compression of the foam typically shows three different sections, as illustrated in Figure 11. ${ }^{[12,49]}$ An increase in stress accompanies the elastic deformation during the initial loading stage until the yield point is reached. Beyond the yield point, a stress plateau is observed where the strain is associated with buckling of the foam cells, resulting in a small increase in stress. Beyond the buckling strain, there is a steep rise in the resistance to deformation and the stress increases very quickly. DiPrima et 
al demonstrated these changes in the foam microstructure during a foam compression cycle. ${ }^{[49]}$ A CT scan of the foam was performed at various compression stages to demonstrate the changes in the cell structure during compression. The image shows that, for the epoxy foam in DiPrima's study, at 20-30\% strain buckling begins and beyond 50\% strain the cells begin to undergo further compaction and become difficult to distinguish. ${ }^{\text {[49] }}$

The peak stresses achieved during the compression depend on a variety of factors such as the maximum strain applied, the temperature of application of strain, the rate of strain application, and the material history. As the temperature of compression increases, the deformation resistance decreases and the peak stresses achieved during deformation decreases for same degree of strain. Again the peak stresses have been observed to increase as the rate of strain application is increased for the same temperature and \%strain. ${ }^{[12]}$ The effect of test temperature was reported by Kang et al. The typical yield, necking and strain hardening stages were distinguishable only in samples in their glassy state with much higher stress values $(\sim 60 \mathrm{kPa})$ as opposed to samples in their rubbery state $(\sim 2-5 \mathrm{kPa}) .{ }^{[18]} \mathrm{Xu}$ et al. reported compressive strength of syntactic SMP foams following UV exposure in their primary or programmed state. ${ }^{[76]}$ The compressive strength was found to decrease by $13.7 \%$ and $10.6 \%$, and yield strain by $7.2 \%$ and $4.6 \%$, for the foam exposed in its primary and programmed shape, respectively. The modulus, however, was seen to increase by $6.2 \%$ and $7.7 \%$ respectively, demonstrating the effect of UV-induced photo-oxidative changes in the material during aging. ${ }^{[76]}$ It is noteworthy that this loading stress-strain behavior is typical in compression testing, but has been shown to differ for flexural and torsional tests aimed towards development of actuator parts in an epoxy based (3 M Scotchkote $206 \mathrm{~N}$ ), one part heat curable SMP resin. ${ }^{[54]}$ After the loading is complete, a quick stress relaxation is typically observed in the samples. The degree of stress relaxation has been shown to be a function of the modulus of the sample and/or filler content. A nanoclay filler (MMT) in epoxy foams, for example, was shown to reduce the stress relaxation of compressed foam samples. ${ }^{[41]}$

After the foams are compressed, they may be unloaded to characterize the hysteresis of the loading-unloading cycle. It is observed that the recovery of strain becomes worse as the temperature during loading decreases from above $\mathrm{Tg}$ to below $\mathrm{Tg}$, leading to a higher dissipation of energy and hysteresis at $\mathrm{T}<\mathrm{Tg} .{ }^{[12]}$ Strain rate is also seen to influence hysteresis; as the strain rate is increased, the maximum stress during loading is increased and the dissipation of energy/hysteresis increases. ${ }^{[12]}$ Also, as the strain increases, the recovery is observed to decrease and the hysteresis increases. ${ }^{[49]}$ The strain was also observed to have an influence on the recovery dynamics; the larger the strain, the faster the recovery occurs during heating in the free strain recovery. ${ }^{[12]}$ Also, if the compression is done in the viscoelastic region of the foam (at a temperature in the transition range), the peak stresses are found to be higher (125 and $95 \mathrm{kPa}$ for compression at 100 and $125^{\circ} \mathrm{C}$, respectively, of a TEMBO 3XE (CTD Inc) foam with $92{ }^{\circ} \mathrm{C} \mathrm{Tg}$ ) and the onset of recovery is found to occur sooner. ${ }^{[49]}$

DiPrima et al. reported work on modeling the constrained stress recovery of $20 \%, 30 \%$ and $40 \%$ relative density TEMBO DP5.1 epoxy based foams. ${ }^{[53]}$ Compression of foams of three different densities was performed at room temperature, $\mathrm{Tg}$ and at $\mathrm{Tg}+20 \mathrm{C}$ for these materials. The theoretical prediction was made for the value of stresses for all conditions based on a modified version of Ashby's model ${ }^{[75]}$, which incorporated the effect of compression temperature via a compressibility modifier term. Good agreement between the experimental and theoretical results was achieved. ${ }^{[53]}$ Singhal et al. also reported constrained stress recovery on low density SMP foams ${ }^{[35]}$ and compared the performance of the reported materials with other SMP foams in the literature using the theoretical scaling of stress with density as proposed by Ashby et al. ${ }^{[75]}$ 
Similar trends of compressive stresses, recovery dynamics and percent recovery for higher foam density and lower temperature of compression were reported by Domeier et al. ${ }^{[62]}$ In general, compression close to $\mathrm{T}_{\mathrm{g}}$ onset appeared to provide optimal recovery performance in terms of high recovery stresses and low hysteresis. ${ }^{[62]}$

Block testing is another interesting variation to conventional compression testing as reported by DiPrima et al. that provides useful insight on the effect of multiple successive steps of loading and unloading as opposed to a single loading step. ${ }^{[49]}$ In this test the maximum desired strain was divided into several equal segments. The sample was loaded to the highest strain value of the first segment, unloaded to a desired preload, then loaded again to the strain level of the second segment, and so on. Complete overlap of the full range of one step compression test with the respective block compression tests was reported for epoxy based TEMBO 3XE foams (CTD).

\subsection{Cyclic Testing}

Cyclic testing of foams is critical for applications that require repeated programming and actuation of the SMP. At least 3-5 cycles are generally reported on SMP foams to be able to better understand their mechanical behavior with respect to fixity, shape or stress recovery and hysteresis in successive cycles. Tobushi et al. performed a full thermomechanical cycle of loading, fixing by cooling to $\mathrm{T}<\mathrm{Tg}$, and then heating to $\mathrm{T}>\mathrm{Tg}$ allowing free strain recovery on Mitsubishi MFNo 21 SMP foams for 10 consecutive cycles. They reported a shape fixity and recovery of $\sim 99-100 \%$ for the foams when compressed at $\mathrm{Tg}+30{ }^{\circ} \mathrm{C}$ to $78 \%$ strain at a rate of $25 \% / \mathrm{min}$ independent of the cycles. ${ }^{[12]}$ Cyclic recovery for epoxy foam samples was performed by DiPrima et al. at three temperatures $\left(80,100,125{ }^{\circ} \mathrm{C}\right)$ for three different strain levels of $40 \%, 60 \%$ and $80 \%$. A higher permanent strain was noticed in the initial few cycles, which then plateaued as the number of cycles increased. The value of permanent strain was found to be higher as the compression was performed at higher strains and also as the temperature of compression was increased. ${ }^{[49]}$ Cyclic testing of low density $(0.015-0.021 \mathrm{~g} / \mathrm{cm} 3)$ foams was performed by Singhal et al., and similar behavior of relatively higher hysteresis was seen in the first few (up to 3 ) cycles, followed by a high shape recovery of $\sim 98 \%$ in subsequent cycles. ${ }^{[35]}$ Another set of cyclic tests on the Mitsubishi MM3520 and MM5520 foams was performed at $~ 50 \%$ strain at $\mathrm{Tg}+20, \mathrm{Tg}$ and Tg-20 by DeNardo, et al. While the MM3520 showed a typical loading-unloading cycle with a decrease in hysteresis areas with progressive cycles, MM5520 showed much higher hysteresis and sample failure probably due to a structural defect. ${ }^{[36]}$

Madbouly et al. reported a free strain recovery of $\sim 85 \%$ for SMP foams based on PPDL and PCL in the first cycle. The second and third cycles gave a higher strain recovery of $\sim 98 \%$. High shape fixity of $\sim 100 \%$ was reported in all cases. ${ }^{[20]}$ Kang et al. also reported cyclic testing up to 4 cycles on polyurethane based foams $(0.052-0.059 \mathrm{~g} / \mathrm{cm} 3)$. The first cycle showed 52-63\% shape recovery, and recovery progressively improved with subsequent cycles. ${ }^{[18]}$ Similarly in inorganic-organic PDMS-PCL SMP foams, slightly low shape recovery of $\sim 85 \pm 10 \%$ was seen across different compositions. This improved to $95 \pm 3 \%$ in the second cycle. A high shape fixity of over $100 \%$ was measured possibly due to temperature or compression induced crystallization of PCL segments leading to a more compact structure. ${ }^{[26]}$

The effect of filler (MMT nanoclay) on the compressive strength of epoxy based foams subjected to cyclic testing was reported by Squeo et al. ${ }^{[55]}$ An increase in the compressive strength was observed with the increase in the filler content as expected. ${ }^{[41,55]}$ However, contrary to typical SMP behavior, a relative increase and then decrease in the compressive strength was noticed in the first and second cycles, respectively, for the different compositions. It was speculated that the compression leads to an ordering of the polymer 
matrix, which was still underway in the second cycle for the foam with higher filler content, leading to an increase in compressive strength. ${ }^{[55]} \mathrm{A}$ high shape recovery of greater than $97 \%$ was reported for these materials irrespective of compressive strength. ${ }^{[41]}$

As discussed above, a drop in maximum stress with successive cycles, prior to accumulation of residual strain and ultimately failure is typically observed in cyclic tests. ${ }^{[68]}$ This behavior has been thought to be due to the changes in the foam macrostructure, such as cell strut damage or breaking of cell membranes. Also micro-structural changes due to residual stresses in the material, and re-arrangement of side groups and dangling ends in the polymer can contribute to such hysteresis. ${ }^{[35]}$ In order to explain the role of changes in the foam macro-structure in this behavior, DiPrima studied the average strut thickness and cell size as a function of number of cycles in thermomechanical testing of epoxy based SMP foams. ${ }^{[67]}$ Although average strut thickness and cell sizes were found to be independent of each other in the pre-failure region, analysis of the local regions showed formation of localized microdamage without disruption of the surrounding structure as seen in Figure 12. These were concluded to have a role in the drop in the maximum normalized stress preceding the accumulation of residual strain as they were expected to reduce the force required for sample compression prior to occurrence of the residual strain. ${ }^{[68]}$

\subsection{Other Characterization Methods}

Constrained stress recovery and free strain recovery tests are typically used for the characterization of the shape memory behavior of SMP foams. However, several other tests have been employed to understand application-specific aspects of SMP behavior. For instance, Huang et al. reported the evolution of stress during cooling/fixing the sample below Tg as a constrained cooling test. ${ }^{[77]}$ Foam samples made from Mitsubishi MF5520 polymer as obtained from Jet Propulsion Labs (JPL) were compressed to various strains at $\sim \mathrm{Tg}+20^{\circ} \mathrm{C}$, and the stress was recorded as they were cooled down to $\sim 27^{\circ} \mathrm{C}\left(\mathrm{Tg}-30^{\circ} \mathrm{C}\right)$. As expected, a decrease in the stress was observed for all samples as they were cooled below $\mathrm{Tg}$. However, at strains greater than $80 \%$, the residual stresses at $\mathrm{T}<\mathrm{Tg}$ were relatively higher than reported on similar materials. ${ }^{[12,77]}$

Response time during actuation of SMP foam materials may be of critical importance, especially for actuator-based applications. Measurement of the sample response time was reported by Simkevitz et al. in which the shape memory speed, based on images of recovering foam as a function of time, and the recovery force, based on the readings of an extension spring scale in series connection with the recovering foam, were measured. ${ }^{[66]}$ It was estimated that higher recovery forces were achieved in foams filled with organoclay Cloisite 20A. Also, faster response times and higher recovery forces were associated with average pore sizes in the range 10-100 um. Styrene based SMP foams were also characterized for their shape recovery ability and speed by Wu et al. ${ }^{[78]}$ Specimens consisted of foam bars that were programmed in a secondary bent shape; the angle between the two halves was 180 degrees in the primary shape (straight) and 0 degrees in the secondary shape (folded in half). At or above a temperature of $70{ }^{\circ} \mathrm{C}\left(\mathrm{Tg}=70{ }^{\circ} \mathrm{C}\right)$, the shape recovery was $100 \%$. The shape recovery speed, however, was not reproducible over different samples or temperatures, which was attributed to non-uniform heat conductivity in the sample bulk due to non-uniform distribution of pores. While the recovery from 0 to 150 degrees was relatively fast and almost linear, recovery from 150 to 180 degrees was slower, with an average recovery rate of 0.83 degrees/sec. ${ }^{[78]}$

Flexural tests on foams aimed towards actuator applications have been reported for composite epoxy (3M ScotchkoteTM $206 \mathrm{~N}$ ) based foams. ${ }^{[41,54]}$ With the addition of a nanoclay (MMT) filler at $3 \mathrm{wt} \%$ to the epoxy resin, the flexural strength was reported to decrease from 7.3 MPa to 4.2 $\mathrm{MPa}$, and the strain-at-failure decreased from $4.5 \%$ to 
$2.7 \% .{ }^{[41]}$ This result was atypical as composite materials are generally observed to become more brittle with lower strains-at-failure, but higher strengths compared to the unfilled resin. Further, the flexural elastic modulus was insensitive to the filler content.

Indentation tests have also been reported on epoxy SMP foams with or without a nanoclay (MMT) filler. ${ }^{[11]}$ As expected, an increase in the load from $\sim 40 \mathrm{~N}$ to $60 \mathrm{~N}$ was observed when $3 \mathrm{wt} \%$ filler was added. The load configuration under this test is similar to the compression tests, except that a triaxial stress state is produced, and relatively localized behavior is tested as opposed to the macro-scale behavior in standard compression tests.

"Auxetic" shape memory of porous polymers is another field that has been studied in the literature. Bianchi et al. reported conventional polyurethane foams that showed a change in their Poisson's ratio, from up to 0.55 in their primary shape to as low as -0.24 under compression or tension with exposure to different temperature profiles. ${ }^{[79,80]} \mathrm{A}$ simultaneous decrease in tangent modulus of up to 9 times was also observed in the materials in their strained auxetic state. Xu et al. reported 2D programming of syntactic SMP foams that enabled the programmed/fixed foam to exhibit auxetic properties. ${ }^{[2]}$

\subsection{Fixity and Recovery After Storage}

Shape fixity of SMP porous materials indicates how well the temporary programmed shape is "fixed" or retained, which can affect material performance. High shape fixity means that a secondary geometry is maintained very effectively, which is very important for packaging applications, as well as any application that is dependent on an SMP's precisely maintaining a secondary geometry to carry out a particular function. Shape fixity is defined as $R_{\mathrm{f}}=\left(\varepsilon_{\mathrm{u}} /\right.$ $\left.\varepsilon_{\mathrm{m}}\right) \times 100$, where $\varepsilon_{\mathrm{u}}$ is the strain after holding at a no-load condition in the deformed state, and $\varepsilon_{\mathrm{m}}$ is the maximum strain applied. The shape fixity of the MF5520 (Mitsubishi Heavy Industries) SMP foam was studied by Tey et al. ${ }^{[81]}$ The foam, which was reported to have a $\mathrm{Tg}$ of $63{ }^{\circ} \mathrm{C}$, was compressed to at least $80 \%$ strain at $\mathrm{T}>\mathrm{Tg}$, then fixed in the compressed shape by lowering the temperature to $\sim \mathrm{Tg}-30^{\circ} \mathrm{C}$ and removing the loading stress. The shape fixity was found to be low, with complete shape recovery occurring within $\sim 4$ days of storage at $\sim \mathrm{Tg}-30{ }^{\circ} \mathrm{C}$ (i.e., the programmed shape was not retained). Further experiments in which the samples were mechanically constrained during storage at $\mathrm{Tg}-30{ }^{\circ} \mathrm{C}$ for up to 2 months to avoid premature recovery showed full recovery of the material upon heating above Tg. Tobushi et al. followed up this study looking more deeply into the effect of fixity of the MF5520 foams stored under various conditions. ${ }^{[70]}$ By fixing the compressed shape at a lower temperature $\left(\mathrm{Tg}-60^{\circ} \mathrm{C}\right)$, maintaining the sample under mechanical constraint for 24 hours at $\mathrm{Tg}-60{ }^{\circ} \mathrm{C}$, and decreasing the unconstrained storage temperature to $\mathrm{Tg}-60{ }^{\circ} \mathrm{C}$, a much higher shape fixity ( 100\%) was reported on similar MF5520 foam compositions stored for up to 6 months. ${ }^{[70]}$ While these changes led to significant improvement in the material performance, it may be useful to control other environmental factors such as humidity for such characterizations. Since SMP foams and polyurethane SMPs are generally affected by presence of moisture ${ }^{[60]}$, moisture in the air may affect these results. Also, determination of fixity from the measurement of actual sample dimensions before and after the storage at $\mathrm{T}<\mathrm{Tg}$ is preferred, as although the stress may be zero at $\mathrm{T}<\mathrm{Tg}{ }^{[12]}$, structural relaxation may set in with time.

Apart from fixity and recovery, other factors of interest are the effects of holding times and holding conditions. Tobushi et al. studied the mechanical properties of Misubishi MF6020 foams to investigate: 1) the effect of storage time at $\mathrm{Tg}-60^{\circ} \mathrm{C}$ for 2 to 180 days, and the effect of maximum strain on recovery, and 2) the effect of various temperature conditions on the shape holding. The samples were compressed to 50\%, $70 \%$ and $80 \%$ strains and stored for periods from 2 hours to 24 days at $\mathrm{Tg}, \mathrm{Tg}+30$ and $\mathrm{Tg}+60{ }^{\circ} \mathrm{C}$. Also, samples were stored for 28 days at $\mathrm{Tg}-30$ and $\mathrm{Tg}-60{ }^{\circ} \mathrm{C}$. It was reported that shape fixity and recovery of $98 \%$ or 
better was obtained irrespective of the storage time or maximum strain at $\mathrm{Tg}-60{ }^{\circ} \mathrm{C}$. However, above $\mathrm{Tg}$, as the temperature or strain increased a progressively higher loss in the shape recovery was seen (as low as $0 \%$ ), which was referred to as secondary-shape forming. ${ }^{[70]}$ A follow-up study by Singhal et al. on low density foams which were kept under $80 \%$ compressive strain at $\mathrm{Tg}+60{ }^{\circ} \mathrm{C}$ for 2 hours resulted in $94 \%$ recovery. The reduced secondary-shape forming was considered to be due to the highly chemically crosslinked polymer network structure as opposed to the traditional physically crosslinked structure of the MF6020 foams. ${ }^{[35]}$

The effect of accelerated aging in UV light of syntactic Veriflex based foams in their primary and programmed states was studied by Xu et al. ${ }^{[76]}$ They noted that polymer chains in a strained/programmed sample have a higher tendency to undergo various chemical changes such as chain scission, cross linking, depolymerization, photolysis, etc. during aging under UV light, highlighting the inherent tendency of the sample to release the imposed strain under favorable conditions.

\section{Applications of Porous SMPs}

A wide range of applications of porous SMP materials have been proposed. Early adopters of porous SMPs include biomedical, aerospace and consumer applications This review will emphasize applications that have demonstrated some degree toward proof-of-concept of the proposed application. The field, however, is in its infancy regarding progress toward applying porous SMPs and, more importantly, engineering the material and structural properties of the SMPs for specific applications.

\subsection{Biomedical Applications}

In general, SMPs have been proposed and developed for a large number of biomedical applications. Numerous reviews of biomedical applications of SMPs are available. ${ }^{[1,4,82,83]}$ Unlike the large number of neat SMP applications documented in the review papers, the dominant focus of porous SMPs has been for embolic vascular devices. These devices seek to take advantage of large shape recovery, large surface area to volume ratios, and tortuous flow. Other potential biomedical applications include scaffolds for filling bone defects, hemostatic sponges, soft tissue scaffolds, and drug-delivery platforms. While this list is nonexhaustive, it highlights applications that take advantage of the volume recovery and surface area advantages of SMP foams.

Metcalfe et al., were the first to demonstrate the embolic potential for SMP porous materials by demonstrating no cytotoxicity, no mutagenicity and a good in vivo healing response. [43] Cytotoxicity of the CHEM polyurethane foam was tested on L-929 mouse fibroblast cells in accordance with the ISO 10993-5 (biological evaluation of medical devices for in-vitro cytotoxicity). Murine L-929 fibroblast cells stained with a neural red solution were examined microscopically, and the optical density of the dye was measured; no toxicity to cells was observed relative to controls. Also, no mutagenicity was reported for the tested CHEM polyurethane foam samples. Ames bacterial reverse mutation was tested in accordance with ISO 10993-3, specifying the tests for genotoxicity, carcinogenicity and reproductive toxicity. In vivo biocompatibility tests of CHEM foams were reported by Metcalfe et al. in dogs. ${ }^{[43]}$ Segments of external jugular veins were harvested in eight dog subjects and sutured using Prolene in an oval cut on the common carotid artery to create aneurysms. CHEM foam blocks were inserted in the aneurysm, and angiographic tests were performed to observe the degree of occlusion of the aneurysms. At three months, the CHEM foam samples showed complete obliteration in one case and some residual neck in another. The primary histological observations included minimal inflammatory reaction, infiltration of fibrocellular tissue and granulation tissue, and thick neointima formation at the neck. 
Cytotoxicity tests similar to those reported by Metcalfe et al. were performed by DeNardo et al. on CHEM3520 and CHEM5520 foams. ${ }^{[36,37]}$ DeNardo et al. also reported cytocompatibility tests of foam samples directly, as opposed to extracts of foams. L-929 fibroblast cells were seeded on disinfected foam samples and cell morphology and MTT assay were studied after specific periods of incubation. Good cytocompatibility was observed in all cases for Mitsubishi CHEM3520 and CHEM5520 foams. ${ }^{[36,37]}$

Singhal et al. used cytokine expression in blood as a measure of biocompatibility of low density polyurethane foams. ${ }^{[35]}$ Human blood was centrifuged to remove supernatant plasma, and whole blood with serum free ex-vivo media was incubated with foam discs and positive and control samples at $37^{\circ} \mathrm{C}$ for 48 hours. Post incubation, the supernatants were tested by ELISA for expression of TNF-a, IL-1 $\beta$, IL-6, IL-8 and IL-12. Low cell activation was induced overall, indicating good biocompatibility of these materials.

In vivo tests of low density SMP foams in porcine aneurysm models were reported. ${ }^{[58]}$ A 90 day implantation study was performed and the harvested aneurysm sites were analyzed by histopathology and SEM. The aneurysm sites were found have almost complete penetration of collagen through the volume of the foam, a thick fibrous cap across the neck of the aneurysm, and a lack of inflammation compared to the Prolene suture.

Additional recent studies documented several key features of using SMP foams as embolic devices. The expansion stresses imposed by an expanding foam on a human vessel were estimated to be ten and two times smaller than rupture stresses for $1.5 \mathrm{x}$ oversized and $2.0 \mathrm{x}$ oversized foams relative to the vessel diameter, respectively. ${ }^{[59]}$ Water flow, which was used to simulate blood flow, through the foam was measured with magnetic resonance imaging. ${ }^{[84]}$ This study showed that the flow through the foam was tortuous and greatly reduced from relative to the inflow velocities. A computational study explored the potential of thermal damage caused by an external heat source driving the foam actuation for transition temperatures above body temperature. ${ }^{[55]}$ Finally, a stent with foam device concept was demonstrated in a scale model of a fusiform aneurysm with catheter delivery. ${ }^{[86]}$

\subsection{Aerospace Applications}

SMP foams have been proposed for applications in space. Large structures used in space such as solar sails, solar arrays, sunshields and radar antennas require heavy and space consuming mechanical mechanisms for deployment and control. New designs are being developed for low mass, low launch volume deployable structures. SMP foams, when recovering from a compressed secondary geometry, can undergo large volumetric expansion with minimal energy input. Consequently, SMP foams have been identified as a potential material to achieve these goals and improve upon current inflatable structure technologies which are complicated and require inflation systems that add to the overall mass and are vulnerable to damage from debris and micrometeorite strikes. In contrast to these systems, proposed SMP foam structures will be low-cost, reliable and self-deployable. Also, the SMP foam will be capable of absorbing energy from any striking object that would otherwise damage the structure. ${ }^{[87]}$ Furthermore, it has been shown that SMP foams can be stored in compressed states for long periods of time with no effect on shape recovery. ${ }^{[70]}$ While integrating a means of heating such systems to induce actuation has been identified as a potential issue, it has been proposed to use a removable thermal blanket capable of converting solar radiation to thermal energy to provide the heat needed for deployment. ${ }^{[87]}$

Many concepts using SMP foams are being examined for use in space. Smaller structures such as nanorover wheels made of SMP foam with a diameter of $6 \mathrm{~cm}^{[87]}$ and foldable 
microcars ${ }^{[77]}$ have been demonstrated in laboratory experiments. However, there is more interest in larger structures.

To construct large boom structures as large as 50 meters in length, truss elements that combine SMP foam with carbon fiber reinforced polymers have been tested. The truss elements were composed of SMP foam blocks sandwiched between ribbons of the carbon fiber reinforced polymer. The foam, which is rigid below its $\mathrm{Tg}$, aids in maintaining the structure's stowed and deployed configurations and also provides buckling resistance to the overall structure. The polymer ribbons give high axial stiffness and overall stability to the structure. Elastic energy stored in the ribbons when rolled into the stowed configuration aids in the deployment of the truss element when the foam is heated. [87]

Another large structure anticipated to benefit from SMP foams is the solar sail. These structures which can be on the order of tens of meters to hundreds of meters in size will propel spacecraft by converting photon momentum from solar radiation into acceleration. Thin films of SMP foam with micron-sized cells are an alternative to concepts for solar sail construction that rely on complicated actuation mechanisms and large support structures. To add functionality to the solar sails, the integration of thin-film electronics, sensors, actuators and power sources into the SMP foam is possible. ${ }^{[88]}$

Attempts have been made to use SMP foams as a component of adaptive airplane wings. When designing aircraft that must perform in multiple regimes, i.e. long range flight or flight requiring high maneuverability, the average efficiency and performance is considered. Thus, the performance within any one regime will be suboptimal. However, work is being done to design new wing structures that adapt to specific flight requirements allowing optimal performance within multiple flight regimes. ${ }^{[47]}$ SMP foams have been tested to eliminate the need for the heavy actuation structures required to produce large enough shape changes necessary to achieve noticeable changes in the performance of small and low speed plane. ${ }^{[89]}$ Perkins and coworkers focused on designing a wing that could make in-flight changes in its chord length thereby increasing or decreasing lift as needed. The initial wing design had a core composed of dynamic modulus foam, a composite foam fabricated from SMP resin, wrapped within a SMP skin. Within the foam, a system of mechanically actuated rods controlled the extent to which the foam was allowed to expand during heat actuation. In testing, the foam did not perform well for two-way expansion leading them to abandon the foam design. ${ }^{[47]}$

\subsection{Robotic Grips}

Monkman and coworkers investigated the use of a commercially available polyurethanebased SMP foam (FLEGMAT, Ranwal Ltd, Great Britain) as an improvement on robotic gripping technology. It was found that the materials compliance was dependent on temperature. Above the material's $\mathrm{Tg}$ of approximately 30C, the material was compliant enough to conform to irregular geometries of an object to be gripped. Also, the high compliance in the high temperature state allows for the gripping of delicate objects that may be damaged by stiffer grips. Below its Tg, the foam's compliance is greatly reduced such that the foam remains firm allowing for the transportation of the object. ${ }^{[56]}$

\subsection{Self-healing applications}

In the last few decades, syntactic foams, fabricated by dispersing microballons or small glass spheres into polymeric matrices, have been frequently used in foam-cored sandwich panels that are employed in a wide range of structural applications. The research of self-healing technology with regards to foam-cored sandwich panels has been of recent interest. ${ }^{\text {[90] }}$ Many schemes have been implemented to stimulate self-healing of damaged foam; however, 
most are only efficient at repairing micro-scale damage. Thus, $\mathrm{Li}$ and coworkers ${ }^{[91]}$ proposed a two-step "close then heal" approach to self-healing. This process utilizes SMPbased syntactic foam as described in Figure 13 to close or fill damage areas, such as cracks or voids, coupled with a healing mechanism such as microcapsules containing material that polymerizes upon release. After the foam is damaged, confined shape recovery is induced via a temperature rise causing the foam to expand into and fill any cracks or voids that may have formed. The effectiveness of this process can be seen in Figure 14 which shows an ultrasonic c-scan of a panel after each of seven impact and healing cycles. The C-scan images give a visual representation of the attenuation of the ultrasound signal through the panel, which is proportional to the damage present, with $20 \%$ attenuation indicated by red color, $20-50 \%$ attenuation by blue color and $100 \%$ attenuation by white color. As the figure shows, even after the 7th impact, the macro-length scale damage can be adequately healed by heating the foam above its $\mathrm{Tg} .{ }^{[90]}$ Because this process is heavily reliant on confinement, a 2D grid was integrated into the foam. This, along with the confinement in the $3^{\text {rd }}$ direction provided by the face sheets, proved to give increased healing efficiency and strength to the overall structure. ${ }^{[92]}$

The concept of self-healing SMP-based syntactic foams has been extended to use as a sealant for expansion joints. The failure of expansion joints, in pavement and bridge decks for example, can be a source of costly structural damage to bridge superstructures. To mitigate expansion joint failure, many types of joint sealants are employed including a variety of foam sealants. However, most foam sealants are prone to failure in at least one of three ways: water infiltration into open cells; loss of compression over time as air is forced out of the foam during compression; and the foam being squeezed out of the joint when thermal expansion of the structural elements causes the joint to narrow. ${ }^{[46]}$

SMP-based syntactic foam sealants exhibit none of the failure modes listed above. First, because the SMP foam is closed celled, water infiltration is not an issue. The foam has been shown to maintain its shape memory properties after many thermomechanical cycles suggesting that it will not lose compression over time. Finally, if properly programmed such that the foam expands in one direction and contracts in the other when heated, as thermal expansion of the concrete elements causes narrowing of the joint, the foam will not be squeezed out. ${ }^{[46]}$

\subsection{Textiles}

In the field of textiles research, SMP foam has been examined as a lightweight, thermally intelligent filler capable of thermal insulation in high temperature conditions. Chung and coworkers ${ }^{[3]}$ studied an open-celled polyurethane-based SMP foam for this purpose. They measured the foam's permeability to air as well as the foam's potential as a thermal insulator. It was found that the foam performed very well as a thermal insulator under high external heat conditions and although air permeability was hindered when the foam was compressed, the foam's large pores allowed for favorable permeability when expanded in high external heat conditions. When the foam is exposed to high environmental temperatures, it expands which improves its thermal isolating properties.

\subsection{Sand Management}

SMP foams have been applied to the area of petroleum engineering as sand management tools in well operations to replace the traditional methods of gravel packing which is complicated and costly and expandable metal screens that do not conform well to the wellbore surface. ${ }^{[94]}$ For this application, SMP foam segments, as long as 6 feet in length, are fabricated to have outer diameters larger than the wellbore with inner diameters for the placement of base pipes. The foam is compressed radially for installation in the well. When 
actuated, the foam conforms to and exerts a force on the sandface of the well holding the foam in place and maintaining an open wellbore. ${ }^{[95]}$ Tests performed by Carrejo and coworkers ${ }^{[96,97]}$ show that SMP foam can adequately filter sand without compromising well productivity. Yuan and coworkers ${ }^{[94]}$ further defined the working conditions under which SMP foam would be beneficial over the traditional gravel packing. It was identified that, because SMP foams have low stiffness at elevated temperatures, their use is not ideal for offshore drilling as the working temperature is over $165 \mathrm{~F}(\sim 74 \mathrm{C})$. Consequently, $145 \mathrm{~F}$ ( $63 \mathrm{C}$ ) was recommended as the max environmental temperature for the use of SMP foams for sand management.

\section{Concluding Remarks}

While this review describes a significant body of work on porous shape memory materials, it is worth noting that the majority of the published literature has appeared after the year 2000 . Although the field of porous polymer materials is maturing, the dynamics of shape recovery adds new and exciting possibilities from chemistry, materials and applications perspectives. Specifically, the high strain recovery of SMP systems enables porous materials to volumetrically and cyclically change shape like few previous materials. With limited published applications of porous SMPs, the field is still being driven by scientific exploration as much or more than commercial ventures/needs. There is still great opportunity for innovation.

From a materials science standpoint, one area that shows tremendous promise is that of multifunctional porous SMPs, which combine shape memory capabilities with other advanced material capabilities. Material systems such as the magnetoresponsive electronspun SMP mesh reported by Gong, et al. and the porous SMP membrane exhibiting two-way shape memory behavior reported by Ahn, et al. exhibit novel material capabilities in addition to a shape memory effect. ${ }^{[3,34]}$ Although a rapidly growing subset of studies on neat SMP materials are targeting multi-functional SMPs, the number of such reported investigations is significantly lower for porous SMPs. Advanced SMPs such as triple shape memory polymers have been well-received by the scientific community and offer interesting avenues of future study. Also of interest are robust thermoset SMPs with novel processing capabilities, which are excellent candidate materials for cellular SMP fabrication by three dimensional micropatterning. ${ }^{[5,69,98,99]}$

From an application standpoint, chemical or drug release is just one example of the impact porous SMPs can have on current state of the art. A cubic centimeter foam can have order of $1000 \mathrm{~cm}^{2}$ of surface area, yielding a large delivery of agent. Assuming an achievable volume compression of $100 x(1 \times 1 \times 10 \mathrm{~mm})$, a very small compressed device can be deployed to release a relatively large load of chemicals or drugs. While an obvious application is medical (e.g. drug releasing hemostatic sponge), there are non-medical possibilities, such as single-use water filtration/sterilization. Although we provide a few specific examples here, a wide range of applications will continue to drive the development of SMP chemistry, porous materials, and device engineering. Our conclusion is that this intersecting field of shape changing polymers and porous materials is in its infancy with great possibilities ahead.

\section{References}

1. Small W IV, Singhal P, Wilson TS, Maitland DJ. Biomedical applications of thermally activated shape memory polymers. Journal of Materials Chemistry. 2010; 20:3356-3366. [PubMed: 21258605]

2. Lendlein A, Kelch S. Shape-memory polymers. Angewandte Chemie - International Edition. 2002; 41:2034-2057. 
3. Liu C, Qin H, Mather PT. Review of progress in shape-memory polymers. Journal of Materials Chemistry. 2007; 17:1543-1558.

4. Yakacki CM, Gall K. Shape-memory polymers for biomedical applications. Advances in Polymer Science. 2010; 226:147-175.

5. Hearon K, Gall K, Ware T, Maitland DJ, Bearinger JP, Wilson TS. Post-polymerization crosslinked polyurethane shape memory polymers. Journal of Applied Polymer Science. 2011; 121:144-153. [PubMed: 21572577]

6. Hearon K, Smith SE, Maher CA, Wilson TS, Maitland DJ. The effect of free radical inhibitor on the sensitized radiation crosslinking and thermal processing stabilization of polyurethane shape memory polymers. Radiation Physics and Chemistry. 2012 10.1016/j.radphyschem.2012.10.007.

7. Sun L, Huang WM, Ding Z, Zhao Y, Wang CC, Purnawali H, Tang C. Stimulus-responsive shape memory materials: A review. Materials and Design. 2012; 33:577-640.

8. Balaji R, Boileau S, Guérin P, Grande D. Design of Porous Polymeric Materials from Miscellaneous Macromolecular Architectures: An Overview. Polymer News. 2004; 29:205-212.

9. Wolfe, PS.; Sell, SA.; Bowlin, GL. Natural and Synthetic Scaffolds. In: Pallua, N.; Suscheck, CV., editors. Tissue Engineering. Springer; New York: 2011. p. 41-67.

10. Osada Y, Gong J-P. Soft and Wet Materials: Polymer Gels. Advanced Materials. 1998; 10:827837.

11. Sokolowski WM, Chmielewski AB, Hayashi S, Yamada T. Cold hibernated elastic memory (CHEM) self-deployable structures. Proceedings of SPIE - The International Society for Optical Engineering. 1999; 3669:179-185.

12. Tobushi H, Okumura K, Endo M, Hayashi S. Thermomechanical properties of polyurethane-shape memory polymer foam. Journal of Intelligent Material Systems and Structures. 2001; 12:283-287.

13. Hentze H-P, Antonietti M. Porous polymers and resins for biotechnological and biomedical applications. Reviews in Molecular Biotechnology. 2002; 90:27-53. [PubMed: 12069045]

14. Ravichandran R, Sundarrajan S, Venugopal JR, Mukherjee S, Ramakrishna S. Advances in Polymeric Systems for Tissue Engineering and Biomedical Applications. Macromolecular Bioscience. 2012; 12:286-311. [PubMed: 22278779]

15. Bettinger CJ. Biodegradable Elastomers for Tissue Engineering and Cell-Biomaterial Interactions. Macromolecular Bioscience. 2011; 11:467-482. [PubMed: 21229578]

16. Hayashi S, Fujimura HU. S. Patent 5049591. 1991

17. Chevalier E, Chulia D, Pouget C, Viana M. Fabrication of porous substrates: A review of processes using pore forming agents in the biomaterial field. Journal of Pharmaceutical Sciences. 2008; 97:1135-1154. [PubMed: 17688274]

18. Kang SM, Lee SJ, Kim BK. Shape memory polyurethane foams. Express Polymer Letters. 2012; 6:63-69.

19. Lee SH, Jang MK, Hee Kim S, Kim BK. Shape memory effects of molded flexible polyurethane foam. Smart Materials and Structures. 2007; 16:2486-2491.

20. Madbouly SA, Kratz K, Klein F, Lützow K, Lendlein A. Thermomechanical behaviour of biodegradable shape-memory polymer foams. Materials Research Society Symposium Proceedings. 2009; 1190:99-104.

21. Simkevitz S, Naguib HE. Development of two part porous shape memory polymer nanocomposites. Proceedings of the ASME Conference on Smart Materials, Adaptive Structures and Intelligent Systems, SMASIS2008. 2008; 1:453-460.

22. Xu T, Li G. A shape memory polymer based syntactic foam with negative Poisson's ratio. Materials Science and Engineering A. 2011; 528:6804-6811.

23. Armentano I, Dottori M, Fortunati E, Mattioli S, Kenny JM. Biodegradable polymer matrix nanocomposites for tissue engineering: A review. Polymer Degradation and Stability. 2010; 95:2126-2146.

24. Freyman TM, Yannas IV, Gibson LJ. Cellular materials as porous scaffolds for tissue engineering. Progress in Materials Science. 2001; 46:273-282. 
25. Murphy WL, Dennis RG, Kileny JL, Mooney DJ. Salt Fusion: An Approach to Improve Pore Interconnectivity within Tissue Engineering Scaffolds. Tissue Engineering. 2002; 8:43-52. [PubMed: 11886653]

26. Zhang D, Burkes WL, Schoener CA, Grunlan MA. Porous inorganic-organic shape memory polymers. Polymer. 2012; 53:2935-2941. [PubMed: 22956854]

27. Chung SE, Park CH. The thermoresponsive shape memory characteristics of polyurethane foam. Journal of Applied Polymer Science. 2010; 117:2265-2271.

28. Sin D, Miao X, Liu G, Wei F, Chadwick G, Yan C, Friis T. Polyurethane (PU) scaffolds prepared by solvent casting/particulate leaching (SCPL) combined with centrifugation. Materials Science and Engineering: C. 2010; 30:78-85.

29. Chung T. New Shape Memory Effects in Semicrystalline Polymeric Networks. Case Western Reserve University. 2009

30. De Nardo L, De Cicco S, Jovenitti M, Tanzi MC, Fare S. Shape memory polymer porous structures for mini-invasive surgical procedures. Proceedings of 8th Biennial ASME Conference on Engineering Systems Design and Analysis, ESDA2006. 2006; 2006:1-6.

31. Schiffman JD, Schauer CL. A Review: Electrospinning of Biopolymer Nanofibers and their Applications. Polymer Reviews. 2008; 48:317-352.

32. Tseng L-F, Mather PT, Henderson JH. A programmable shape-changing scaffold for regenerative medicine. 2012 38th Annual Northeast Bioengineering Conference, NEBEC 2012: Philadelphia, PA. 2012:227-228. art. no. 6207046.

33. Ahn J-S, Woong-Ryeol Y, Ji Ho Y, Hee Youk R. In situ temperature tunable pores of shape memory polyurethane membranes. Smart Materials and Structures. 2011; 20:105024.

34. Gong T, Li W, Chen H, Wang L, Shao S, Zhou S. Remotely actuated shape memory effect of electrospun composite nanofibers. Acta Biomaterialia. 2012; 8:1248-1259. [PubMed: 22186162]

35. Singhal P, Rodriguez JN, Small W, Eagleston S, Van De Water J, Maitland DJ, Wilson TS. Ultra low density and highly crosslinked biocompatible shape memory polyurethane foams. Journal of Polymer Science, Part B: Polymer Physics. 2012; 50:724-737.

36. De Nardo L, Alberti R, Cigada A, Yahia L, Tanzi MC, Farè S. Shape memory polymer foams for cerebral aneurysm reparation: Effects of plasma sterilization on physical properties and cytocompatibility. Acta Biomaterialia. 2009; 5:1508-1518. [PubMed: 19136318]

37. De Nardo L, Moscatelli M, Silvi F, Tanzi MC, Yahia L, Farè S. Chemico-physical modifications induced by plasma and ozone sterilizations on shape memory polyurethane foams. Journal of Materials Science: Materials in Medicine. 2010; 21:2067-2078. [PubMed: 20407808]

38. Sauter T, Lützow K, Schossig M, Kosmella H, Weigel T, Kratz K, Lendlein A. Shape-Memory Properties of Polyetherurethane Foams Prepared by Thermally Induced Phase Separation. Advanced Engineering Materials. 2012; 14:818-824.

39. Gurevitch I, Silverstein MS. Shape memory polymer foams from emulsion templating. Soft Matter. 2012

40. Gill, AA.; Claeyssens, F. 3D Structuring of Biocompatible and Biodegradable Polymers Via Stereolithography. In: Haycock, JW., editor. 3D Cell Culture. Humana Press; United States: 2011. p. 309-321.

41. Quadrini F, Santo L, Squeo EA. Solid-state Foaming of Nano-Clay-Filled Thermoset Foams with Shape Memory Properties. Polymer - Plastics Technology and Engineering. 2012; 51:560-567.

42. Sokolowski W, Ghaffarian R. Surface control of cold hibernated elastic memory self-deployable structure. Proceedings of SPIE - The International Society of Optical Engineering: San Diego, CA. 2006; 6167:61670Y.

43. Metcalfe A, Desfaits A-C, Salazkin I, Yahia LH, Sokolowski WM, Raymond J. Cold hibernated elastic memory foams for endovascular interventions. Biomaterials. 2003; 24:491-497. [PubMed: 12423604]

44. De Nardo L, Bertoldi S, Tanzi MC, Haugen HJ, Farè S. Shape memory polymer cellular solid design for medical applications. Smart Materials and Structures. 2011:20.

45. Restrepo D, Mankame ND, Zavattieri PD. Shape memory polymer based cellular materials. Conference Proceedings of the Society for Experimental Mechanics Series. 2011; 3:105-111. 
46. Li G, Xu T. Thermomechanical characterization of shape memory polymer-based self-healing syntactic foam sealant for expansion joints. Journal of Transportation Engineering. 2011; 137:805-814.

47. Perkins DA, Reed JL Jr, Havens E. Adaptive wing structures. Proceedings of SPIE - The International Society for Optical Engineering. 2004; 5388:225-233.

48. Lu H, Gou J. Fabrication and electroactive responsive behavior of shape-memory nanocomposite incorporated with self-assembled multiwalled carbon nanotube nanopaper. Polymers for Advanced Technologies. 2012

49. Di Prima MA, Lesniewski M, Gall K, McDowell DL, Sanderson T, Campbell D. Thermomechanical behavior of epoxy shape memory polymer foams. Smart Materials and Structures. 2007; 16:2330-2340.

50. Radford DW, Antonio A. Enhancing the deformation of shape memory sandwich panels. Strain. 2011; 47:534-543.

51. Radford, DW.; Antonio, A. Shape memory sandwich panels. 17th International Conference on Composite Materials; Edinburgh. 2009;

52. Vialle G, Di Prima M, Hocking E, Gall K, Garmestani H, Sanderson T, Arzberger SC. Remote activation of nanomagnetite reinforced shape memory polymer foam. Smart Materials and Structures. 2009; 18:115014.

53. Di Prima M, Gall K, McDowell DL, Guldberg R, Lin A, Sanderson T, Campbell D, Arzberger SC. Deformation of epoxy shape memory polymer foam. Part I: Experiments and macroscale constitutive modeling. Mechanics of Materials. 2010; 42:304-314.

54. Fabrizio Q, Santo L, Anna SE. Shape memory epoxy foams for space applications. Materials Letters. 2012; 69:20-23.

55. Squeo EA, Quadrini F. Shape memory epoxy foams by solid-state foaming. Smart Materials and Structures. 2010:19.

56. Monkman GJ, Taylor PM. Memory foams for robot grippers. Proceedings of the fifth International Conference on Advanced Robotics. 1991; 1:339-342.

57. Wilson TS, Bearinger JP. U.S. Patent US20060036045A1. 2006

58. Rodriguez JN, Yu YJ, Miller MW, Wilson TS, Hartman J, Clubb FJ, Gentry B, Maitland DJ. Opacification of shape memory polymer foam designed for treatment of intracranial aneurysms. Annals of Biomedical Engineering. 2012; 40:883-897. [PubMed: 22101759]

59. Hwang W, Volk BL, Akberali F, Singhal P, Criscione JC, Maitland DJ. Estimation of aneurysm wall stresses created by treatment with a shape memory polymer foam device. Biomechanics and Modeling in Mechanobiology. 2012; 11:715-729. [PubMed: 21901546]

60. Yu YJ, Hearon K, Wilson TS, Maitland DJ. The effect of moisture absorption on the physical properties of polyurethane shape memory polymer foams. Smart Materials and Structures. 2011; 20:085010. [PubMed: 21949469]

61. Chung SE, Park CH, Yu W-R, Kang TJ. Thermoresponsive shape memory characteristics of polyurethane electrospun web. Journal of Applied Polymer Science. 2011; 120:492-500.

62. Domeier L, Nissen A, Goods S, Whinnery LR, McElhanon J. Thermomechanical characterization of thermoset urethane shape-memory polymer foams. Journal of Applied Polymer Science. 2010; 115:3217-3229.

63. Baker RM, Henderson JH, Mather PT. Poly(caprolactone) shape memory scaffold for bone tissue engineering. 2012 38th Annual Northeast Bioengineering Conference, NEBEC 2012: Philadelphia, PA. 2012:309-310. art. no. 6207088.

64. Karimi M, Heuchel M, Weigel T, Schossig M, Hofmann D, Lendlein A. Formation and size distribution of pores in poly( $\varepsilon$-caprolactone) foams prepared by pressure quenching using supercritical CO 2. Journal of Supercritical Fluids. 2012; 61:175-190.

65. Gall K, McDowell DL, Di Prima MA, Lesniewski M, Sanderson T, Campbell D. Cyclic and monotonic behavior of epoxy shape memory polymer foam. Huangshan. :2008819.

66. Simkevitz SL, Naguib HE. Fabrication and analysis of porous shape memory polymer and nanocomposites. High Performance Polymers. 2010; 22:159-183. 
67. Di Prima MA, Gall K, McDowell DL, Guldberg R, Lin A, Sanderson T, Campbell D, Arzberger SC. Deformation of epoxy shape memory polymer foam: Part II. Mesoscale modeling and simulation. Mechanics of Materials. 2010; 42:315-325.

68. Di Prima MA, Gall K, McDowell DL, Guldberg R, Lin A, Sanderson T, Campbell D, Arzberger SC. Cyclic compression behavior of epoxy shape memory polymer foam. Mechanics of Materials. 2010; 42:405-416.

69. Ware T, Hearon K, Lonnecker A, Wooley KL, Maitland DJ, Voit W. Triple-Shape Memory Polymers Based on Self-Complementary Hydrogen Bonding. Macromolecules. 2012; 45:10621069. [PubMed: 22287811]

70. Tobushi H, Matsui R, Hayashi S, Shimada D. The influence of shape-holding conditions on shape recovery of polyurethane-shape memory polymer foams. Smart Materials and Structures. 2004; 13:881-887.

71. Tobushi H, Hayashi S, Endo M, Shimada D. Creep and stress relaxation of polyurethane-shape memory polymer foam. Transactions of the Japan Society of Mechanical Engineers, Part A. 2002; 68:1788-1793.

72. Tobushi H, Okumura K, Endo M, Hayashi S. Thermomechanical properties of polyurethane-shape memory polymer foam. Journal of Intelligent Material Systems and Structures. 2001; 12:283-287.

73. Cui J, Kratz K, Heuchel M, Hiebl B, Lendlein A. Mechanically active scaffolds from radio-opaque shape-memory polymer-based composites. Polymers for Advanced Technologies. 2011; 22:180189.

74. Singhal P, Boyle A, Infanger S, Letts W, Small W IV, Yu Y-J, Maitland DJ, Wilson TS. Controlling the Actuation Rate of Low Density Shape Memory Polymer Foams in Water. Macromolecular Chemistry \& Physics. 2012 in press.

75. Ashby M, Medalist R. The mechanical properties of cellular solids. Metallurgical and Materials Transactions A. 1983; 14:1755-1769.

76. Xu T, Li G, Pang SS. Effects of ultraviolet radiation on morphology and thermo-mechanical properties of shape memory polymer based syntactic foam. Composites Part A: Applied Science and Manufacturing. 2011; 42:1525-1533.

77. Huang WM, Lee CW, Teo HP. Thermomechanical behavior of a polyurethane shape memory polymer foam. Journal of Intelligent Material Systems and Structures. 2006; 17:753-760.

78. Wu X, Liu Y, Leng J. Study on shape recovery speed of SMP, SMP composite and SMP foam. Proceedings of SPIE - The International Society for Optical Engineering. 2008:6931. art. no. 69310D.

79. Bianchi M, Scarpa F, Smith CW, Whittell GR. Physical and thermal effects on the shape memory behaviour of auxetic open cell foams. Journal of Materials Science. 2010; 45:341-347.

80. Bianchi M, Scarpa F, Smith CW. Shape memory behaviour in auxetic foams: Mechanical properties. Acta Materialia. 2010; 58:858-865.

81. Tey SJ, Huang WM, Sokolowski WM. Influence of long-term storage in cold hibernation on strain recovery and recovery stress of polyurethane shape memory polymer foam. Smart Materials \& Structures. 2001; 10:321-325.

82. Lendlein A, Behl M, Hiebl B, Wischke C. Shape-memory polymers as a technology platform for biomedical applications. Expert Review of Medical Devices. 2010; 7:357-379. [PubMed: 20420558]

83. El Feninat F, Laroche G, Fiset M, Mantovani D. Shape memory materials for biomedical applications. Advanced Engineering Materials. 2002; 4:91-104.

84. Small W IV, Gjersing E, Herberg JL, Wilson TS, Maitland DJ. Magnetic resonance flow velocity and temperature mapping of a shape memory polymer foam device. BioMedical Engineering Online. 2009:8. [PubMed: 19405976]

85. Ortega J, Maitland D, Wilson T, Tsai W, Savaş Ö, Saloner D. Vascular dynamics of a shape memory polymer foam aneurysm treatment technique. Annals of Biomedical Engineering. 2007; 35:1870-1884. [PubMed: 17676399]

86. Small W, Buckley PR, Wilson TS, Benett WJ, Hartman J, Saloner D, Maitland DJ. Shape Memory Polymer Stent With Expandable Foam: A New Concept for Endovascular Embolization of Fusiform Aneurysms. Biomedical Engineering, IEEE Transactions on. 2007; 54:1157-1160. 
87. Sokolowski WM, Tan SC. Advanced self-deployable structures for space applications. Journal of Spacecraft and Rockets. 2007; 44:750-754.

88. Sokolowski W, Tan S, Willis P, Pryor M. Shape memory self-deployable structures for solar sails. Proceedings of SPIE - The International Society for Optical Engineering. 2008:7267. art. no. 72670K.

89. Sofla AYN, Meguid SA, Tan KT, Yeo WK. Shape morphing of aircraft wing: Status and challenges. Materials \&amp; Design. 2010; 31:1284-1292.

90. Li G, John M. A self-healing smart syntactic foam under multiple impacts. Composites Science and Technology. 2008; 68:3337-3343.

91. Li G, Nettles D. Thermomechanical characterization of a shape memory polymer based selfrepairing syntactic foam. Polymer. 2010; 51:755-762.

92. John M, Li G. Self-healing of sandwich structures with a grid stiffened shape memory polymer syntactic foam core. Smart Materials and Structures. 2010:19.

93. Chung Y-C, Cho TK, Chun BC. Flexible cross-linking by both pentaerythritol and polyethyleneglycol spacer and its impact on the mechanical properties and the shape memory effects of polyurethane. Journal of Applied Polymer Science. 2009; 112:2800-2808.

94. Yuan Y, Goodson J, Johnson M, Gerrard D. In-situ mechanical and functional behavior of shape memory polymer for sand management applications. Brasil Offshore Conference and Exhibition: Macae, Rio de Janeiro. 2011; 1:417-426.

95. Ozan C, Van Der Zee W, Brudy M, Vinson J. Mechanical modeling of shape memory polyurethane foam for application as a sand management solution. SPE Annual Technical Conference and Exhibition: Denver, CO. 2011; 3:2210-2219.

96. Carrejo N, Horner DN, Johnson MH. Shape memory polymer as a sand management alternative to gravel packing. Canadian Unconventional Resources Conference: Alberta, Canada. 2011; 1:408420.

97. Carrejo N, Horner DN, Johnson SH. The effects of dynamic loading on the sand management and permeability of shape memory polymer and gravel packs for sand management applications. Brasil Offshore Conference and Exhibition: Macae, Rio de Janeiro. 2011; 1:203-211.

98. Park JS, Darlington T, Starr AF, Takahashi K, Riendeau J, Thomas Hahn H. Multiple healing effect of thermally activated self-healing composites based on Diels-Alder reaction. Composites Science and Technology. 2010; 70:2154-2159.

99. Hearon K, Nash L, Volk BL, Ware T, Lewicki JP, Voit. WE, Wilson TS, Maitland DJ. Electron Beam Crosslinked Polyurethane Shape Memory Polymers with Tunable Mechanical Properties. Macromolecular Chemistry \& Physics. 2012 10.1002/macp.201200348.

100. Livshin S, Silverstein MS. Crystallinity in Cross-Linked Porous Polymers from High Internal Phase Emulsions. Macromolecules. 2007; 40:6349-6354. 

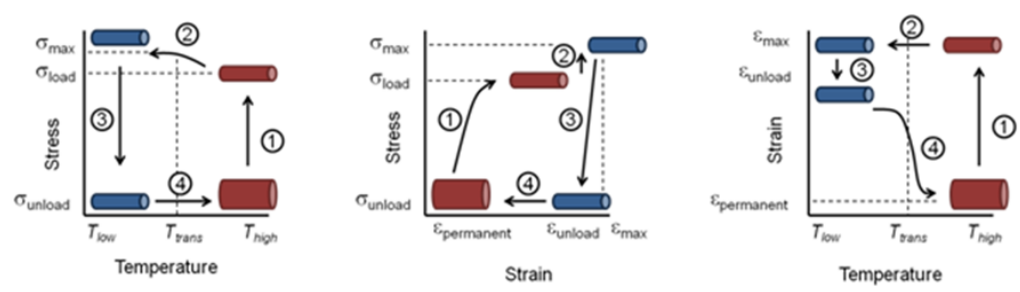

Figure 1.

Illustration of the shape memory cycle in stress/temperature, stress/strain, and strain/ temperature planes. Step 1 is isothermal loading, Step 2 is cooling at constant load, Step 3 is isothermal unloading, and Step 4 is shape recovery upon heating under load-free conditions. 


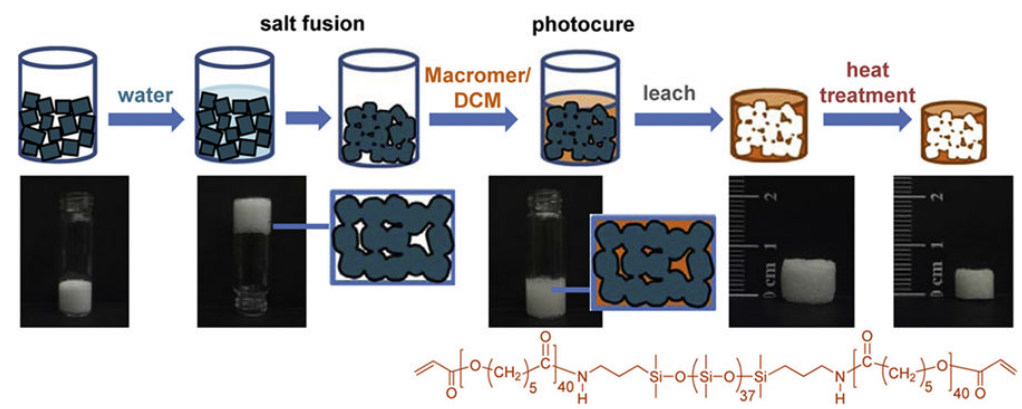

Figure 2.

Schematic of salt fusion and leaching method of three-dimensional foam fabrication. The figure is reproduced with permission from ${ }^{[26]}$. 


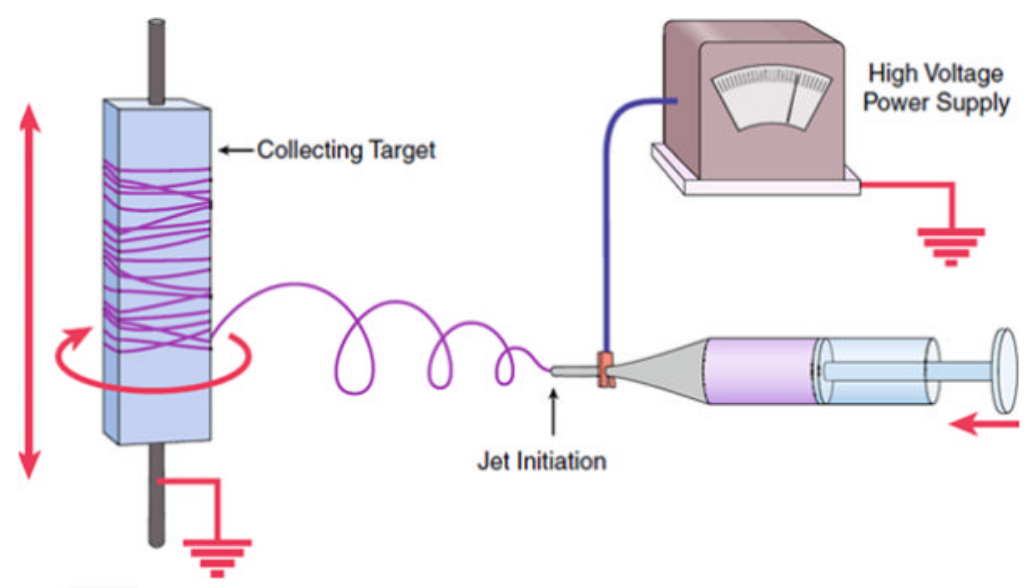

Figure 3.

Illustration of an electrospinning setup. The figure is reproduced with permission from ${ }^{[9]}$. 


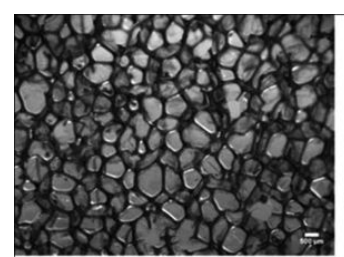

H80

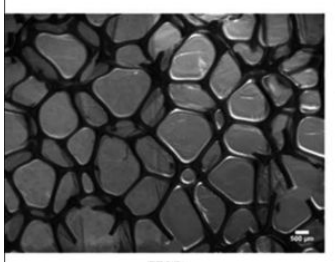

H20

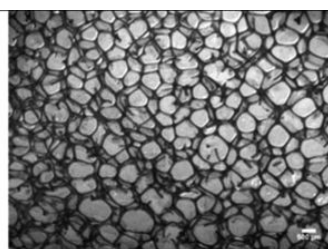

H60

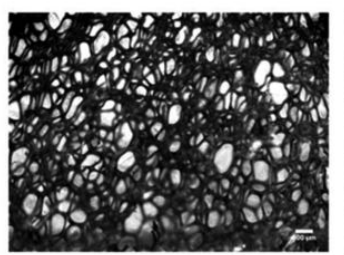

H0

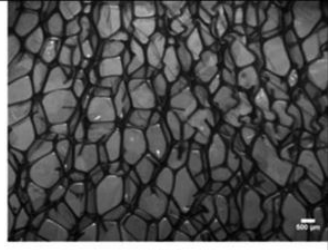

$\mathrm{H} 40$

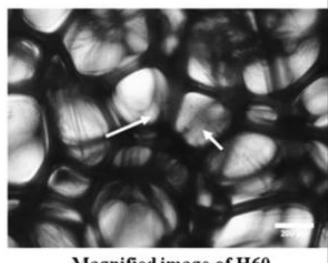

Magnified image of $\mathrm{H} 60$

Figure 4.

Cell structure of thermoset polyurethane gas blown foams as obtained from optical microscopy of thin slices of the material. Scale bar is $500 \mathrm{um}$. The images are reproduced with permission from ${ }^{[35]}$. 

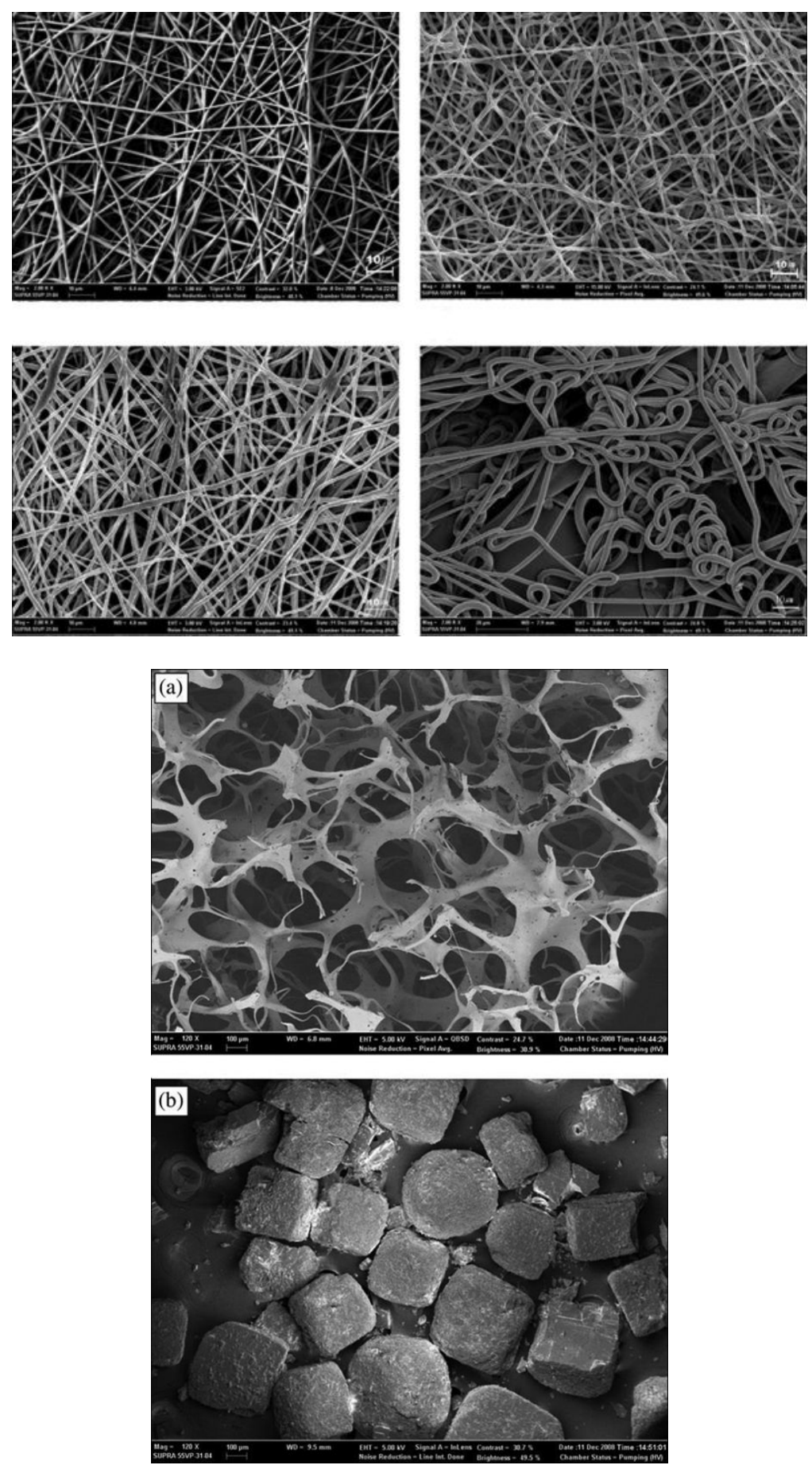

Figure 5.

(a) Electrospun web mesh structural comparison for polyurethane SMP electrospun in varying percent solution obtained by field emission scanning electron microscopy. Scale bar is $10 \mu \mathrm{m}$. The images are reproduced with permission from [61]. (b) Porous PCLpolyurethane SMP foam scaffold obtained by salt leaching and image of salt particles obtained by field emission scanning electron microscopy. Scale bar is $100 \mu \mathrm{m}$. The images are reproduced with permission from ${ }^{[27]}$. 


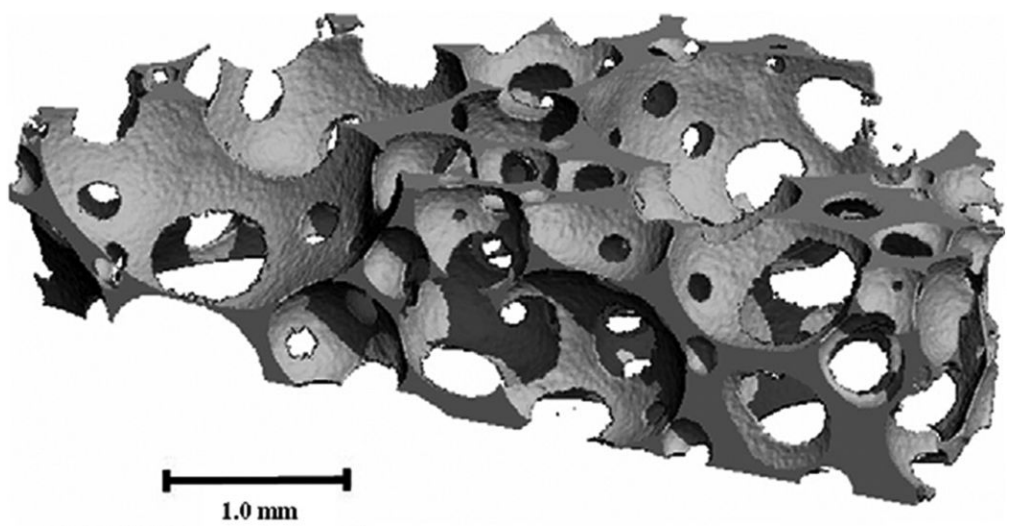

Figure 6.

A 3D X-ray micro CT image of an epoxy based SMP foam. The image is reproduced with permission from ${ }^{[49]}$. 


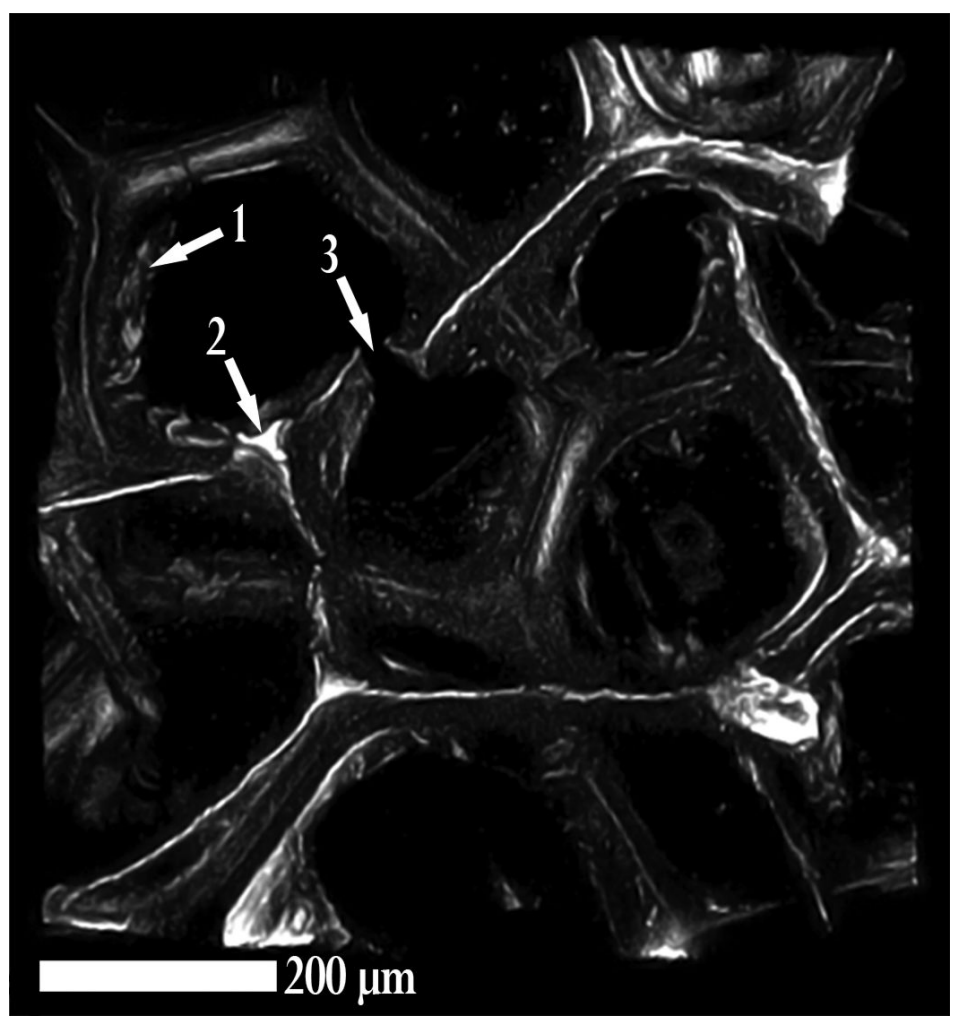

Figure 7.

A 3D confocal image of a polyurethane low density foam based on the $\mathrm{H} 60$ composition of ${ }^{[35]}$ llustrates the pore network, a reticulated membrane (arrow 1), strut crossection (arrow 2 ), and a damaged strut (arrow 3 ) of the polymer foam. The resolution of the technique is approximately $1,1,5$ micrometers (x,y,z: $\mathrm{z}$ depth). The scale bar is $200 \mu \mathrm{m}$. 

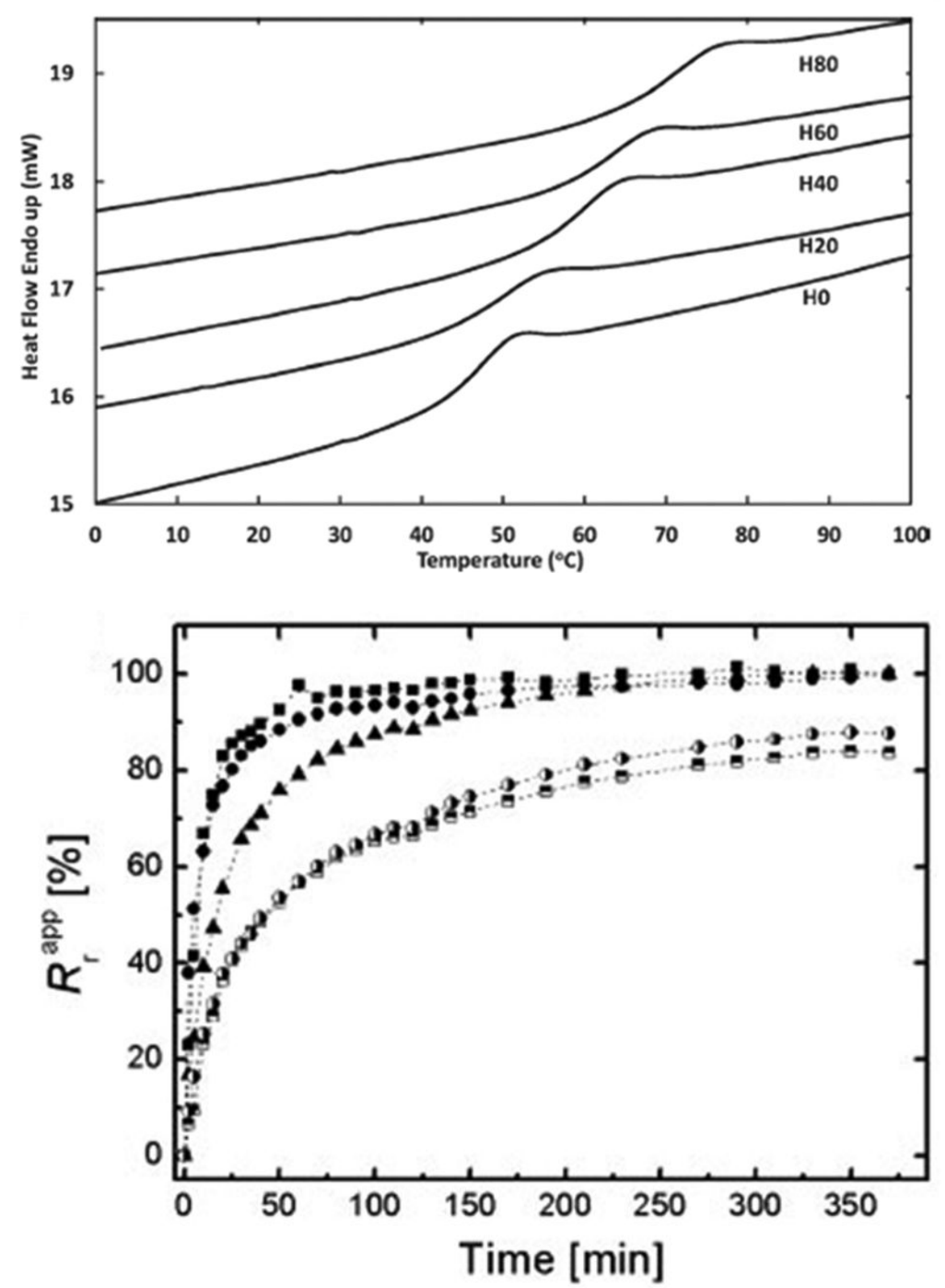

Figure 8.

(a) DSC curves illustrating Tg tunability of thermoset polyurethane SMP foams. This image is reproduced with permission from ${ }^{[35]}$. (b) Shape recovery vs. time isotherms illustrating tunability of $\mathrm{T}_{\text {trans. }}$. This image is reproduced with permission from ${ }^{[73]}$. 


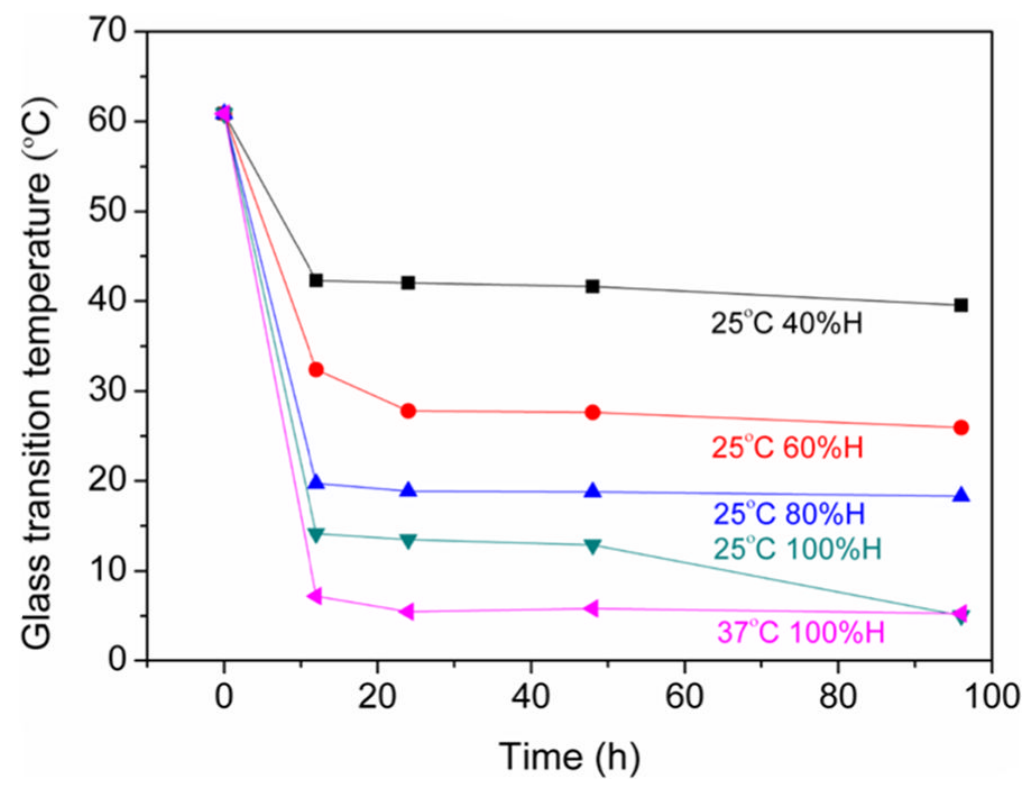

Figure 9.

Effect of moisture absorption on Tg of thermoset polyurethane SMP foam. The image is reproduced with permission from ${ }^{[60]}$. 


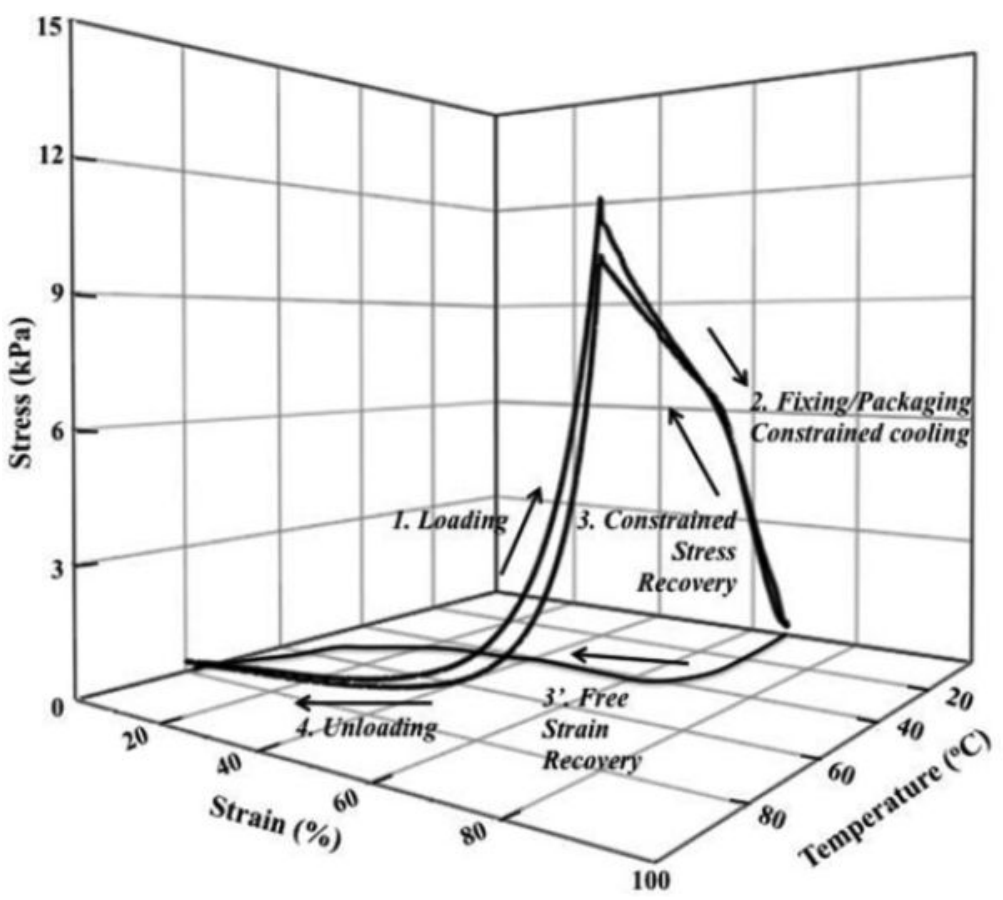

Figure 10.

Steps representing the shape memory thermo-mechanical cycle. The figure is reproduced with permission from ${ }^{[35]}$. 

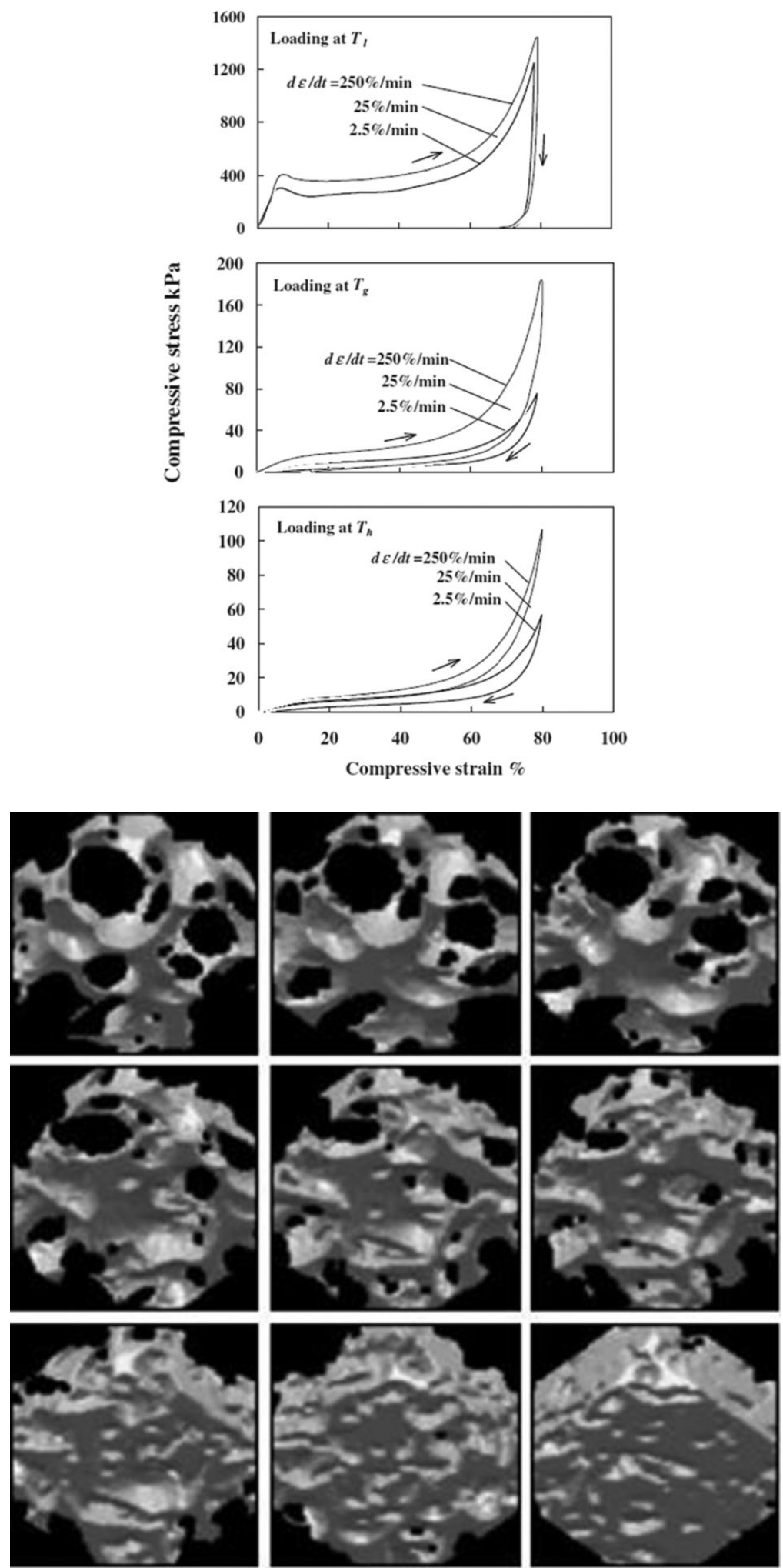


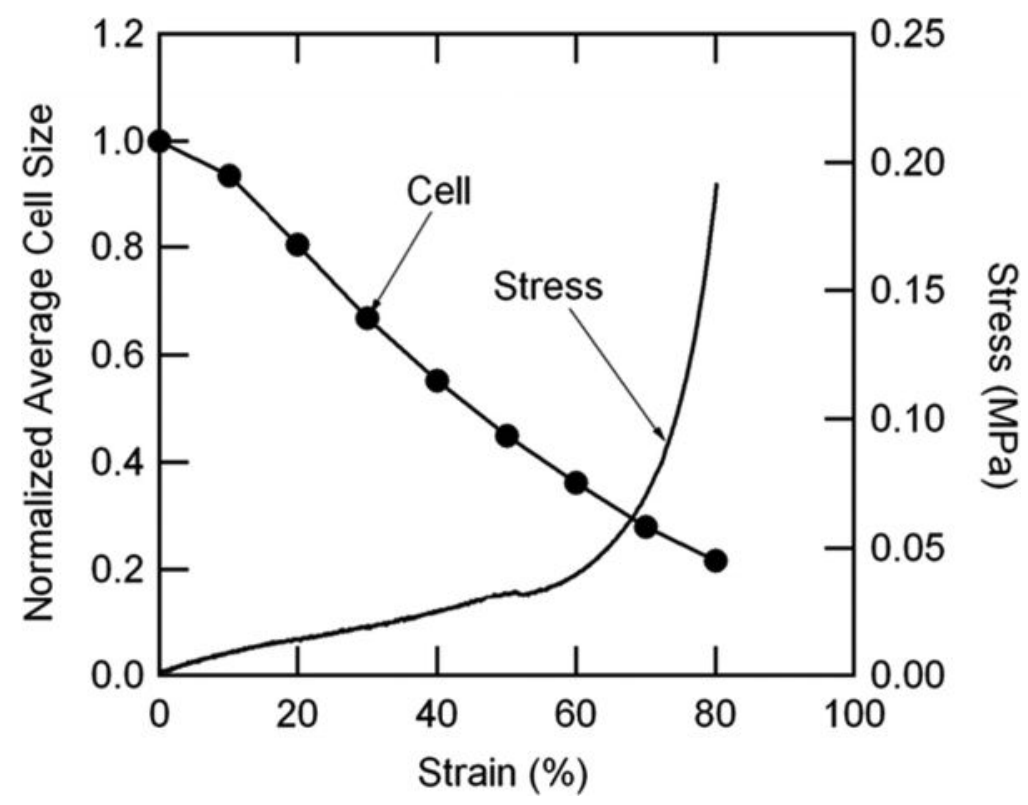

Figure 11.

(a) The evolution of stress with respect to compressive strain at different temperatures and strain rates on Mitsubishi MFNo21 foams. The figures are reproduced with permission from ${ }^{[12]}$. (b) (Top) Change in cell size and stress as a function of compressive strain in epoxy based SMP foams, (Bottom) CT scan images of an epoxy based foam at progressively higher compressive strains. The figure is reproduced with permission from ${ }^{[49]}$. 

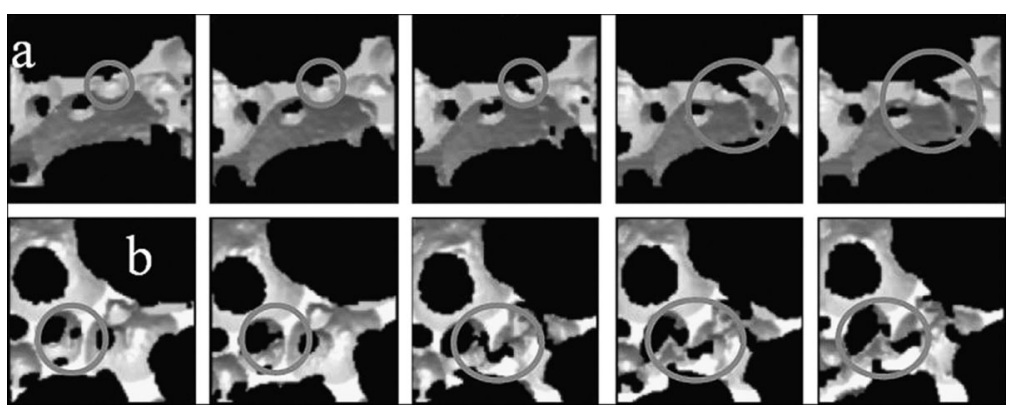

Figure 12.

Examples of microfracturing of struts prior to macroscopic sample failure. (a) and (b) track two different struts at $0,25,50,75$ and 100 cycles respectively going from left to right. The figures are reproduced with permission from ${ }^{[68]}$. 

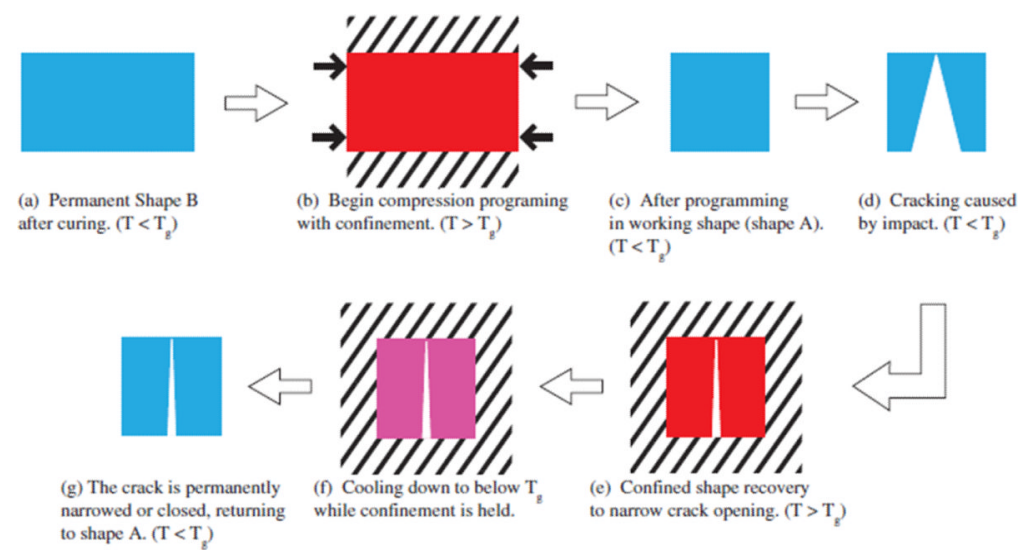

Figure 13.

Schematic of the self-closing scheme of the proposed smart foams (Tg is the transition temperature of the foams). The figure is reproduced with permission from [91]. 

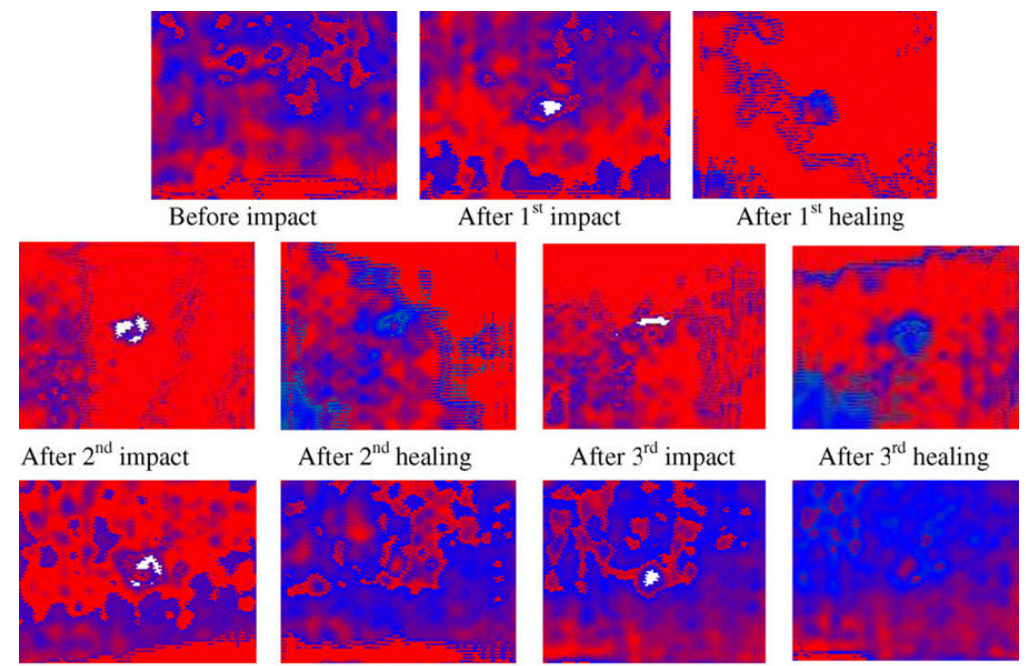

After $2^{\text {nd }}$ healing

After $3^{\text {rd }}$ impact

After $3^{\text {rd }}$ healing
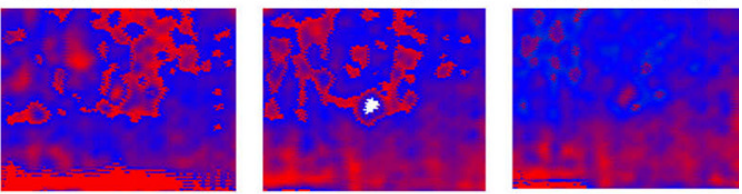

After $4^{\text {th }}$ impact

After $4^{\text {th }}$ healing

After $5^{\text {th }}$ impact

After $5^{\text {th }}$ healing

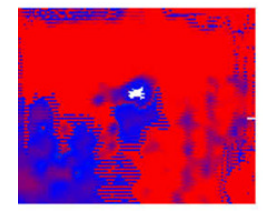

After $6^{\text {th }}$ impact

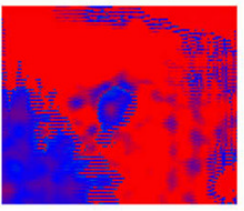

After $6^{\text {th }}$ healing

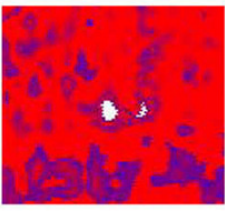

After $7^{\text {th }}$ impact

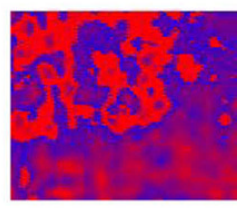

After $7^{\text {th }}$ healing

Figure 14.

$\mathrm{C}$-scan images of the sandwich panels after each impact and healing cycle. The figure is reproduced with permission from ${ }^{[90]}$. 


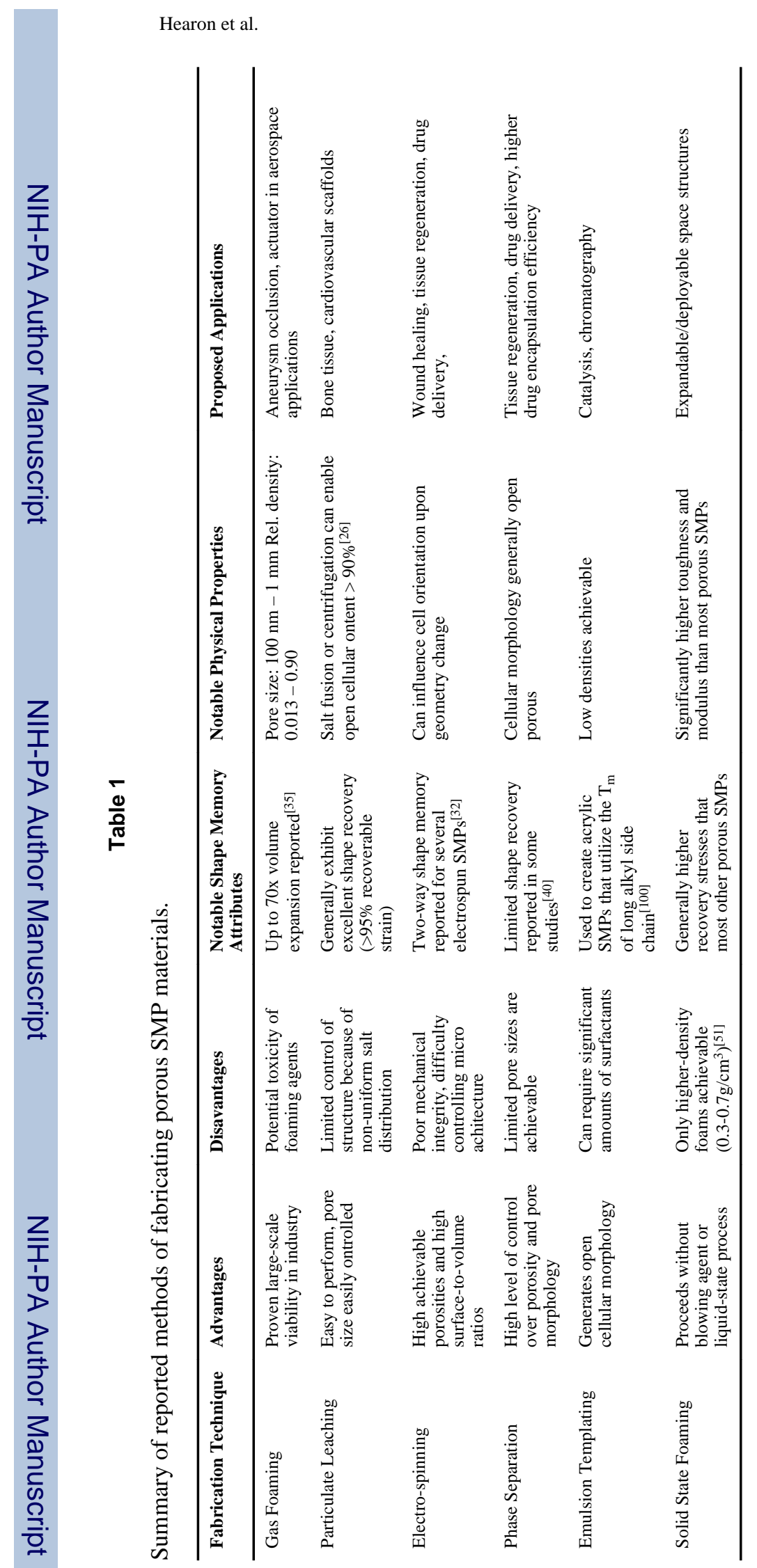

Polym Rev (Phila Pa). Author manuscript; available in PMC 2014 February 04. 
Table 2

Comparison of chemical compositions, physical, and material properties of porous SMP materials reported in the literature.

\begin{tabular}{|c|c|c|c|c|}
\hline Material & Procured From & Density & Modulus & $\mathbf{T}_{\text {trans }}$ \\
\hline CHEM Polyurethane Foam & Mitsubishi, Jet Propulsion Lab & $0.032 \mathrm{~g} / \mathrm{cm}^{3}$ & - & $60^{\circ} \mathrm{C}\left(\mathrm{T}_{\mathrm{g}}\right)^{[43]}$ \\
\hline MF5520 Foam & Mitsubishi Heavy Industries & - & - & $\begin{array}{l}63^{\circ} \mathrm{C}\left(\mathrm{T}_{\mathrm{g}}\right),{ }^{[81]} 64^{\circ} \mathrm{C} \\
\left(\mathrm{T}_{\mathrm{g}}\right)^{[77]}\end{array}$ \\
\hline MF No. 21 Foam & Mitsubishi Heavy Industries & - & $10 \mathrm{MPa}$ & $55^{\circ} \mathrm{C}\left(\mathrm{T}_{\mathrm{g}}\right)^{[12]}$ \\
\hline $\begin{array}{l}\text { TEMBO® 3XE 2-part epoxy } \\
\text { foam }\end{array}$ & $\begin{array}{l}\text { Composite Technology } \\
\text { Development (CTD) }\end{array}$ & $0.20 \mathrm{~g} / \mathrm{cm}^{3}$ & $50 \mathrm{MPa}$ & $92 \pm 3^{\circ} \mathrm{C}\left(\mathrm{T}_{\mathrm{g}}\right)^{[49]}$ \\
\hline $\begin{array}{l}\text { TEMBO® DP.5.1 2-part epoxy } \\
\text { foam }\end{array}$ & $\begin{array}{l}\text { Composite Technology } \\
\text { Development (CTD) }\end{array}$ & $\mathrm{RD} 0.20,0.30,0.40$ & $60-120 \mathrm{MPa}$ & $83-88^{\circ} \mathrm{C}\left(\mathrm{T}_{\mathrm{g}}\right)^{[53,67]}$ \\
\hline CHEM 3520 Polyurethane Foam & Mitsubishi, Jet Propulsion Lab & $0.12 \mathrm{~g} / \mathrm{cm}^{3}$ & $10-20 \mathrm{MPa}$ & $32^{\circ} \mathrm{C}\left(\mathrm{T}_{\mathrm{g}}\right)^{[36]}$ \\
\hline \multirow[t]{2}{*}{ CaloMER 48 Foam } & $\begin{array}{l}\text { Polymer Technology Group, } \\
\text { Berkeley, CA; Blowing agents } \\
\text { Plastronfoam BSH and W16 }\end{array}$ & $0.85-0.91 \mathrm{~g} / \mathrm{cm}^{3}$ & $1000 \mathrm{MPa}$ & $61-89^{\circ} \mathrm{C}\left(\mathrm{T}_{\mathrm{g}}\right)^{[44]}$ \\
\hline & $\begin{array}{l}\text { Polymer Technology Group, } \\
\text { Berkeley, CA; Prepared by salt } \\
\text { leaching } 20,50,70 \mathrm{wt} \% \mathrm{NaCl}\end{array}$ & $0.67-1.11 \mathrm{~g} / \mathrm{cm}^{3}$ & $1000 \mathrm{MPa}$ & $82-89^{\circ} \mathrm{C}\left(\mathrm{T}_{\mathrm{g}}\right)^{[44]}$ \\
\hline $\begin{array}{l}\text { Veriflex }{ }^{\circledR} \text { polystyrene syntactic } \\
\text { foam ( } 2 \text { part thermoset resin } \\
\text { system: Part A has styrene, } \\
\text { divinyl benzene and vinyl } \\
\text { neodecanoate, Part B has benzoyl } \\
\text { peroxide) }\end{array}$ & $\begin{array}{l}\text { CRG Industries SMP, Potter's } \\
\text { Industries glass microballoons }\end{array}$ & $0.08-0.14 \mathrm{~g} / \mathrm{cm}^{3}$ & $845 \mathrm{MPa}$ & $64-71^{\circ} \mathrm{C}\left(\mathrm{T}_{\mathrm{g}}\right)^{[90]}$ \\
\hline $\begin{array}{l}\text { Polyurethane foam from MDI, } \\
\text { diethanolamine, ester type polyols } \\
\text { (ethylene glycol, } 1-4 \text { butane } \\
\text { glycol, adipic acid) }\end{array}$ & $\begin{array}{l}\text { Gas blowing (DC2583 silicone } \\
\text { surfactant; BL-22, BL-11 blowing } \\
\text { catalyst, Dabco 33LV gelling } \\
\text { catalyst) }\end{array}$ & $0.22-0.30 \mathrm{~g} / \mathrm{cm}^{3}$ & $20 \mathrm{MPa}$ & $20^{\circ} \mathrm{C}\left(\mathrm{T}_{\mathrm{g}}\right)^{[19]}$ \\
\hline $\begin{array}{l}\text { Polyurethane foam } \\
\text { (Hexamethylene Diisocyanate } \\
\text { (HDI), Trimethyl hexamethylene } \\
\text { diisocyanate (TMHDI), } \\
\text { Triethanolamine (TEA), Hydroxy } \\
\text { propyl ethylene diamine (HPED). }\end{array}$ & $\begin{array}{l}\text { Gas Blowing (DC5179, DCI } 990 \\
\text { surfactants, BL-22 blowing } \\
\text { catalyst, T-131 gelling catalyst, } \\
\text { Enovate and water-blowing } \\
\text { agents) }\end{array}$ & $0.015-0.027 \mathrm{~g} / \mathrm{cm}^{3}$ & 0.15-0.30 MPa (shear) & $44-86^{\circ} \mathrm{C}\left(\mathrm{T}_{\mathrm{g}}\right)^{[35]}$ \\
\hline $\begin{array}{l}\text { Poly ester-urethane, from Poly } \\
\text { caprolactone triol }\left(\mathrm{M}_{\mathrm{n}}=4000 \mathrm{Da}\right) \text {, } \\
\text { MDI and 1,4-butanediol }\end{array}$ & $\begin{array}{l}\text { Salt leaching; } \mathrm{PU} \text { dissolved in } \\
\mathrm{THF}, \mathrm{NaCl} \text { poragen }\end{array}$ & $0.11 \mathrm{~g} / \mathrm{cm}^{3}$ & - & $31^{\circ} \mathrm{C}\left(\mathrm{T}_{\mathrm{m}}\right)^{[27]}$ \\
\hline $\begin{array}{l}3 \mathrm{M} \text { Skotchkote } 206 \mathrm{~N} \text { one part } \\
\text { heat curable epoxy resin }\end{array}$ & Solid State Foaming & $0.35-0.65 \mathrm{~g} / \mathrm{cm}^{3}$ & $80-220 \mathrm{MPa}$ & $100-105^{\circ} \mathrm{C}\left(\mathrm{T}_{\mathrm{g}}\right)^{[55]}$ \\
\hline
\end{tabular}

